\title{
A Review of Tree Species Classification Based on Airborne LiDAR Data and Applied Classifiers
}

\author{
Maja Michałowska ${ }^{*, t, \ddagger(D)}$ and Jacek Rapiński $, t, \pm(D)$ \\ Institute of Geodesy and Civil Engineering, Faculty of Geoengineering, \\ University of Warmia and Mazury in Olsztyn, 10-724 Olsztyn, Poland; jacek.rapinski@uwm.edu.pl \\ * Correspondence: maja.michalowska@uwm.edu.pl \\ † Current address: Prawocheńskiego 15, 10-724 Olsztyn, Poland \\ $\ddagger$ These authors contributed equally to this work.
}

check for

updates

Citation: Michałowska, M.; Rapiński,

J. A Review of Tree Species

Classification Based on Airborne

LiDAR Data and Applied Classifiers. Remote Sens. 2021, 13, 353.

https://doi.org/10.3390/rs13030353

Academic Editor: Lin Cao and Alfonso Fernández-Manso

Received: 21 November 2020

Accepted: 19 January 2021

Published: 20 January 2021

Publisher's Note: MDPI stays neutral with regard to jurisdictional clai$\mathrm{ms}$ in published maps and institutional affiliations.

Copyright: (C) 2021 by the authors. Licensee MDPI, Basel, Switzerland. This article is an open access article distributed under the terms and conditions of the Creative Commons Attribution (CC BY) license (https:// creativecommons.org/licenses/by/ $4.0 /)$.

\begin{abstract}
Remote sensing techniques, developed over the past four decades, have enabled large-scale forest inventory. Light Detection and Ranging (LiDAR), as an active remote sensing technology, allows for the acquisition of three-dimensional point clouds of scanned areas, as well as a range of features allowing for increased performance of object extraction and classification approaches. As many publications have shown, multiple LiDAR-derived metrics, with the assistance of classification algorithms, contribute to the high accuracy of tree species discrimination based on data obtained by laser scanning. The aim of this article is to review studies in the species classification literature which used data collected by Airborne Laser Scanning. We analyzed these studies to figure out the most efficient group of LiDAR-derived features in species discrimination. We also identified the most powerful classification algorithm, which maximizes the advantages of the derived metrics to increase species discrimination performance. We conclude that features extracted from full-waveform data lead to the highest overall accuracy. Radiometric features with height information are also promising, generating high species classification accuracies. Using random forest and support vector machine as classifiers gave the best species discrimination results in the reviewed publications.
\end{abstract}

Keywords: LiDAR; ALS; forestry; tree species; classification

\section{Introduction}

Forest inventories, consisting of the systematic collection of information about forests, covers various spatial scales, from the stand level to the woodlot level, and from the regional to national and global levels. Depending on the purpose of the inventory, different scales require different levels of detail [1]. Getting complete information about a single tree in traditional forest inventory is a challenging task. Inspecting large tracts of forest areas is labor-, time-, and cost-intensive. Moreover, there exists a risk of not carrying out a comprehensive assessment of all trees due to potentially limiting factors, such as the area's topography preventing entry to specific territories, a lack of access to protected areas, or areas with dangerous wildlife [2]. Obtaining the spatial composition of tree species is crucial for economic, ecological, and technical reasons, as well as being essential for forest inventory. The importance of tree species maps has been highlighted in publications, as standalone products for forest management and planning [3,4], as input for species-specific growth and yields model, or for species-specific allometric models [5]. During the last four decades, remote sensing (RS) techniques have developed into a standard in large-scale forest inventory [1,6-14]. The acquisition of high-resolution data using RS techniques with a relatively small set of field sample plots allows for the efficient and automated forest inventory of large areas. Analysis on remote sensing data dedicated to forestry have become an alternative to traditional inventory methods. Unfortunately, tree species identification constitutes a bottleneck in remote sensing-based forest inventory. In optical remote-sensed imagery, the differentiating features overlap, and bidirectional reflectance 
makes the analysis difficult. Recent developments in active remote sensing, particularly Light Detection and Ranging (LiDAR) technology, have demonstrated great potential in forest mapping, due to their capability to gather a three-dimensional point cloud of a forest environment in a short time $[15,16]$. Laser scanning may be provided at:

1. Terrestrial level (Terrestrial Laser Scanning, TLS) for, among others, architectural heritage [17,18], buildings [19-21], roads [22], and bridges [23,24]; or

2. airborne level (Airborne Laser Scanning, ALS), using a flying platform (aircraft, helicopter, or Unmanned Aerial Vehicle; UAV), for aerial objects such as forests [25-27] or urban environments [28,29].

Airborne Laser Scanning systems consist of, among other things, a laser scanner, a Global Positioning System (GPS) receiver, and an Inertial Measurement Unit (IMU). The laser scanner uses laser light as an emission energy source and detects extremely minute energy returns from distant surfaces. The laser scanner's principle is to generate, release, and capture reflected light radiation, as well as recording the associated data. The characteristics of distant objects can be determined based on changes in the return energy from object backscatter, while knowing the characteristics of the emitted laser light. The $3 \mathrm{D}$ positions of all measured points can be calculated when the laser scanner's position and orientation are known. This is why a GPS receiver is used to register the flying platform's position, while the IMU simultaneously records attitude parameters at every measurement time [16,30]. Airborne laser scanning has gained acceptance as a rapid and accurate method for collecting georeferenced data as a three-dimensional point clouds for forest and urban environment surveying. Many publications have presented promising results for determining tree parameters based on LiDAR data. The studies performed so far have concerned the determination of parameters such as the location of the tree trunk, height, crown size, crown base height [31-33], species [27,34,35], type of the tree [36], stem volume [37-41], diameter at breast height [37], and biomass [42]. LiDAR data has been found to be advantageous for tree detection, being less affected by occlusions and shading than passive optical data [43-45]. Tree detection corresponds to the extraction of data that represents a tree, or a group of trees, in an entire geospatial data set. There are two commonly used approaches to relate source data to ground-measured response variables: Area-based approach (ABA) and individual tree crown (ITC) methods [46-48]. ABA methods provide statistically calibrated maps of forest stand parameters, which are useful for large-area inventories. ITC is referred to as single tree extraction, the smallest unit in the forest inventory, to present the spatial distribution of a single tree and its basic features (e.g., height, species, crown size) [48,49]. Latifi et al. (2015) emphasized that both ABA and ITC methods are appropriate for forest inventory. Naturally, these methods have some advantages over the others: ABA does not for allow the recognition of individual tree characteristics, while ITC does not detect trees in the understory and young, dense forest stands. A considerable group of raster-based approaches is available for single tree extraction which uses a canopy height model (CHM), a raster surface interpolated from LiDAR points hitting the tree canopy surface, as basic information. CHM methods have been often used in commercial and business environments, due to the speed of processing and format accessibility of the software. Unfortunately, these methods introduce errors and uncertainties due to the interpolation methods, grid spacing [50], or CHM smoothing filters [51,52]. These errors affect the subsequent estimation of tree metrics, leading to underestimation or overestimation of tree height. Over the years, more sophisticated methods for tree delineation on LiDAR data have been explored and described, with normalized-cut segmentation, supervoxel algorithms, graph-based approaches, and others [46,53-57]. Tree segmentation is an essential step in obtaining the characteristics of the specified object used in the classification. Accurate and proper extraction of the object is a key to achieving high accuracy in determining the object's features, which have an impact on species classification results $[48,58,59]$. To ensure and improve the correctness of tree extraction, manual or semi-manual approaches for tree identification have been used in many studies $[43,60,61]$. 
Unfortunately, manual and semi-manual tree extraction is time-consuming and challenging to implement in large-scale data sets.

The motivation for writing this review was an interest in the commercial market for species recognition based solely on LiDAR data. We reviewed research on tree species classification based on LiDAR data acquired by ALS. The objective of this article answering the following questions:

1. What LiDAR features are the most effective for tree species classification?

2. What is the most effective classification algorithm to take maximum advantage of the information extracted from LiDAR data to potentially increase the accuracy of tree species classification?

The remainder of this article is structured as follows: Section 2 describes the review procedure, quantification of species classification efficiency, and LiDAR-derived features and classifiers that might be used for species discrimination. Section 3 presents the results of an analysis of the effectiveness of LiDAR metrics and classifiers in species classification. Finally, in Section 4, our conclusions and discussions are drawn.

\section{Materials and Methods}

\subsection{Review Approach}

In this paper, we review recent publications about tree species classification performed on ALS data, with LiDAR-derived features used for the classification. In total, 44 publications were reviewed. From these publications, we dismantled comparative studies into sub-studies and treated them as individual cases. In this way, we obtained 97 study cases in total. We would like to point out that some reviewed publications described experiments based on LiDAR data combined with diverse sensor data (e.g., multispectral, hyperspectral, satellite imagery). We have included them in this review, but only within the scope that corresponds to LiDAR data [42,59,62-68].

The reviewed tree species classification studies presented many approaches to species classification using LiDAR-derived metrics. Scanning data was acquired under various conditions and using different sensors. There were different referenced data, very often different species to be recognized, and different methods of tree segmentation. In this paper, we focus only on verifying the effectiveness of groups of features and algorithms in species discrimination. We analyzed their performance by comparing the accuracies developed in every experiment.

\subsection{Accuracy of Species Classification}

The overall accuracy $(\mathrm{OA})$ and, usually, the $\kappa$ coefficient were calculated to quantify the species classification capability in the studies. The overall accuracy is calculated from the number of trees correctly classified relative to the total number of trees, while the $\kappa$ coefficient is the proportion of chance-expected disagreements that do not occur, or the proportion of agreement after the chance agreement is removed from consideration. $\kappa$ is calculated by Equation (1) [69]:

$$
\kappa=\frac{N * \sum_{i=1}^{m} X_{i i}-\sum_{i=1}^{m}\left(X_{i+} * X_{+i}\right)}{N^{2}-\sum_{i=1}^{m}\left(X_{i+} * X_{+i}\right)},
$$

where:

$\mathrm{N}$-the total number of samples,

$X_{i i}$ - the value on the diagonal of the confusion matrix,

$m$-the number of classes/species, and

$X_{i+}, X_{+i}$-the sums of values on the $i$ th row and $i$ th column, respectively.

There is an agreed explanation for the $\kappa$ coefficient, the value of which ranges from -1 to 1 . When $\kappa$ is less than 0 , it indicates less than chance agreement; $\kappa$ from 0.01 to 0.20 indicates slight agreement; $0.21-0.40$ : fair agreement; $0.41-0.60$ : moderate agreement; 
0.61-0.80: substantial agreement; and $\kappa$ from 0.81 to 0.99 indicates almost perfect agreement [70]. Following Wang and Liu (2018), classification approaches that develop high overall accuracy also produce a high $\kappa$ coefficient. $\kappa$ values can be significantly lower than the overall accuracy. This might be observed in tree classification results, when the number of delineated species is too small or when there is a dominant species with a vast sample size [71].

Additionally, we analyzed the Number of Categories Adapted Index (NOCAI) to compare the accuracy of species classification. We calculated NOCAI due to suggestions that it is a more reasonable comparator than overall accuracy [71,72]. NOCAI is calculated by Equation (2):

$$
\text { NOCAI }=O A * \frac{1}{k} * 100 \%
$$

where:

$O A-$ overall accuracy, and

$k$ - the number of identified species $\left(\frac{1}{k}\right.$ is expected to be achieved if trees were randomly assigned to a species).

NOCAI provides a more legitimate basis for comparison when different numbers of species are identified, by excluding the influence of species number in a defined approach. Higher NOCAI values suggest that the developed approaches for tree species classification are more efficient [72].

\subsection{Lidar Features for Tree Species Classification}

LiDAR data represent scanned objects in point cloud form. Every measured point stores additional information that might be used during the classification process. LiDARderived features can be classified into three major groups: geometric, radiometric, and full-waveform features. Geometric metrics describe the point cloud structure representing an object (or part of it) in 3D space. Radiometric parameters relate to the point's radiometric characteristics, while full-waveform metrics are characteristics assigned to the backscatter waveform [73].

All LiDAR-derived metrics can be determined based on a series of features derived from laser scanning, referring to vertical and horizontal structure of the scanned objects point cloud, the intensity of the backscattered signal, number of returns and return number, and parameters from the full-waveform decomposition. Structure parameters with the assistance of other LiDAR features, such as discrete-return intensity, return or echo types, and full-waveform intensity response can help to obtain complex information for forest inventory, especially for tree classification.

\subsubsection{Geometric-Point Cloud}

Laser scanning registers different tree foliage distribution and canopy branching structures, which are often typical for the specified species, thus helping with their recognition during species classification [74,75]. Geometric features used for tree species classification represent the tree's shape and geometry, or those of its parts [73]. Apart from height information, more complex LiDAR-derived geometric metrics that represent tree spatial neighborhoods in 3D or 2D (two-dimensional), such as grid, raster, voxel, or height layers of neighboring points, are valuable. Geometric features are regularly expressed in statistics, such as the arithmetic mean of the normalized height, standard deviation of normalized height, range of normalized height of all points, ratios of crown base height to tree height, ratios of crown volume to the crown area, and more. As well as a vast range of height statistics, there are many features describing the point distribution, such as kurtosis, skewness, penetration, percentiles of height distribution of points in the cluster, density, and number of points in the 10th level layer of the tree height $[34,35,59,76]$. Geometric tree features that might be obtained from LiDAR data, along with detailed definitions, are given in Table 1. 
Table 1. Geometric features extracted from normalized LiDAR data.

\begin{tabular}{|c|c|}
\hline Feature & Definition \\
\hline $\mathrm{H}_{\max }$ & Maximum of the normalized height of all points \\
\hline $\mathrm{H}_{\min }$ & $\begin{array}{l}\text { Arithmetic mean of normalized height of all points above stated in meters } \\
\text { threshold }\end{array}$ \\
\hline $\mathrm{H}_{s t d}$ & $\begin{array}{l}\text { Standard deviation of normalized height of all points above stated in } \\
\text { meters threshold }\end{array}$ \\
\hline $\mathrm{H}_{\text {med }}$ & Median of the normalized height of all points \\
\hline $\mathrm{H}_{\text {range }}$ & Range of normalized height of all points above stated in meters threshold \\
\hline $\mathrm{HP}_{10}$ to $\mathrm{HP}_{90}$ & $\begin{array}{l}10 \% \text { to } 90 \% \text { percentiles of normalized height of all points above stated in } \\
\text { meters threshold with a } 10 \% \text { increment }\end{array}$ \\
\hline $\mathrm{P}$ & $\begin{array}{l}\text { Penetration as a ratio between number of returns below stated meter and } \\
\text { total returns }\end{array}$ \\
\hline CA & Crown area as the area of 2D convex hull \\
\hline $\mathrm{CV}$ & Crown volume as the 3D convex hull \\
\hline $\mathrm{CD}$ & $\begin{array}{l}\text { Crown equivalent diameter calculated from crown area considering crown } \\
\text { as a circle }\end{array}$ \\
\hline As & $\begin{array}{l}\text { Asymmetry as a difference between two crown diameters taken in two } \\
\text { directions }\end{array}$ \\
\hline dns & Canopy density \\
\hline $\mathrm{D}_{1}$ to $\mathrm{D}_{10}$ & $\begin{array}{l}\text { Density at a fixed height. } D_{i}=N_{i} / N_{\text {total }} \text {, where } i=1 \text { to } 10, N_{i} \text { is the } \\
\text { number of points within } i \text { th layer when tree height was divided into } 10 \\
\text { intervals starting from specified meter, } N_{\text {total }} \text { is the number of all points }\end{array}$ \\
\hline
\end{tabular}

The shape of the tree crown might be advantageous for species recognition, as it is species-dependent. This has been confirmed, by Ørka et al. (2009), who pointed out that the major difference between spruce and birch is the rounder crown of birch and the conical shape of a spruce crown. Holmgren et al. (2008) indicated that Scots pine can be separated from spruce and deciduous trees based on the tree's relative crown base height, as Scots pine has a higher crown base than other species. However, Holmgren et al. (2008) emphasized that the height of the base crown varies in the group of species and may depend on factors not included in the classification process. Axelsson et al. (2018), for tree species classification, used geometric features to identify variations between species with large leaves and a dense crown and other species with thinner leaves and a sparser crown. Spheroid-type ellipsoid layers fitted to the tree's crown points defined differences in density and reflectance inside and outside the crown. This approach allowed the authors to find structural and spectral combinations for species recognition. Their experiment results indicated that the outer ellipsoid layers, as the highest horizontal layer of the tree crown, were highly ranked as one of the most effective features for species discrimination [76]. The same conclusions have been reported in previous investigations by Heinzel and Koch (2011) and Shi et al. (2018).

There have been many investigations in which the features of the crown's internal structure were identified and used for species classification. Li et al. 2013 developed algorithms to describe the internal structure of an individual tree crown and to test the effectiveness of those features for species recognition. LiDAR-derived features characterized the 3D texture, foliage clustering degree relative to tree envelope, foliage clustering scale, and gap distribution of an individual tree in horizontal and vertical directions. The approach developed an overall accuracy of $77.5 \%(\kappa=0.7)$ for the classification of four species. Li et al. 2013 emphasized that the extraction of trees performed in the experiment needed improvement, such that the overall accuracy of classification could be even higher. Harikumar et al. (2017) presented a method of conifer species classification based on internal and external crown structure features. They defined new internal crown features using a novel internal branch structure model. This model uses a 3D region growing and principal component analysis to precisely delineate the branch structure. The proposed 
approach developed an overall accuracy of $93.7 \%$ for species classification; its effectiveness was also confirmed in conifer species recognition. Further experiments with the recommended method are needed, to consider the effects on the modeling process of crown overlap and understory vegetation, damaged trees with missing branches, or trees with non-symmetrical crown shapes. Features that represent the internal crown structure are useful in tree species classification [77-79]. Extraction of such features requires highly dense LiDAR data. The reviewed studies confirmed that the species classification effectiveness depends, among others, on the point cloud density [77,80,81]. Höfle et al. (2012) [82] investigated the effect of data density on classification and showed that classification accuracies remain relatively stable for point densities higher than 5 points $/ \mathrm{m}^{2}$. Li et al. 2013 investigated a positive linear correlation $\left(R^{2}=0.88\right)$ between the LiDAR data point density and species classification accuracy. Their examination showed that higher overall accuracy of species classification was developed on the dense point cloud: For a point density of $2-5$ points $/ \mathrm{m}^{2}$ the overall accuracy was approximately $50 \%$ while for over 50 points $/ \mathrm{m}^{2}$, the overall accuracy increased to $70 \%$.

Some reviewed studies have shown that using geometric features solely for species classification generates low overall accuracy, compared to the classification accuracy obtained while using radiometric features, a combination of geometric and radiometric metrics, or full-waveform metrics. Observed misclassifications while using only geometric features might be due to many factors, such as similarities of morphology among different species, structural variations within the same species, the point cloud density, and so on. LiDAR height distribution might be useful for species discrimination for the forest tree species with different heights, but ineffective for multi-layered forest stands with smaller trees below the top-most canopy layer [83].

Therefore, species classification based on LiDAR-derived geometric features remains a demanding task in different types of forests [59].

\subsubsection{Radiometric-Intensity and Reflection Type}

The maximum energy of the backscattered echo, which represents the reflectivity of every point measured by the laser scanner as an intensity [16], has been demonstrated to be a useful and very promising feature in the tree species classification process $[36,74,75,83,84]$. Intensity features that might be derived from single-channel ALS data, along with explanations, are given in Table 2.

Table 2. Single-channel intensity features derived from LiDAR data.

\begin{tabular}{ll}
\hline Feature & Definition \\
\hline $\mathrm{I}_{\min }$ & Minimum of intensity \\
$\mathrm{I}_{\max }$ & Maximum of intensity \\
$\mathrm{I}_{m}$ & Mean of intensity \\
$\mathrm{I}_{s t d}$ & Standard deviation of intensity \\
$\mathrm{I}_{c v}$ & Coefficient of variation of intensity \\
$\mathrm{I}_{m e d}$ & Median of intensity \\
$\mathrm{I}_{s k}$ & Skewness of intensity \\
$\mathrm{I}_{\text {range }}$ & Range of intensity \\
$\mathrm{I}_{k u t}$ & Kurtosis of intensity \\
$\mathrm{I}_{10 t o 90}$ & Intensity value at percentiles from $10 \%$ to $90 \%$ with $10 \%$ increment \\
\hline
\end{tabular}

The backscattered signal intensity is related to the foliage type, leaf size, leaf orientation, and foliage density $[43,80,85]$. Many studies have presented that the combination of LiDAR height information with radiometric features could achieve the complementary advantages of different details and generate better results for species classification $[34,76,79,80,83,86]$. Intensity features generate a higher accuracy of tree species discrimination when used together with geometric features, compared to the results generated with geometric or radiometric features alone $[34,76,79,83,86,87]$. Zhang and Liu (2012), while researching the effectiveness 
of classifiers for tree species classification, analyzed three sets of LiDAR features—structural features alone, intensity features alone, and a combination of structural and intensity features-for the classification of three species. Their results showed that intensity features alone generated lower overall accuracy $(\mathrm{OA}=75.4 \%)$ of species classification than structural features alone $(\mathrm{OA}=88.6 \%)$, while a combination of both variables yielded better overall accuracy $(\mathrm{OA}=92.8 \%)$. You et al. $(2020)$ also studied species classification based on LiDAR height, intensity, and a combination of height and intensity parameters. Their results showed that structural features generated the lowest overall accuracy $(\mathrm{OA}=87.54 \%)$, not the intensity features, as in the study of Zhang and Liu (2012). The combination of both features gave the best overall accuracy (OA $=92.35 \%)$, in agreement with the results of Zhang and Liu (2012). Lin and Hyyppä (2016) proposed a modular framework for species classification based on deriving LiDAR data feature parameters of point-distribution, laser pulse intensity, crown (internal), and tree (external) structures. The accuracy of species classification based on point-distribution features generated the lowest overall accuracy $(65.0 \%)$, as in other studies [83]. Intensity features generated $80.0 \%$ overall accuracy, crown-internal categorized $85.0 \%$, while the integration of all individual optimal parameters generated the highest classification overall accuracy of $92.5 \%$. The approach proposed by Lin and Hyyppä (2016) was presented as an effective tree species classification framework that, among others, reduces the complexity of determining which combination of feature parameters gives the best classification result.

In many studies, the type of reflection has been analyzed for species classification. Ørka et al. (2010, 2012) analyzed LiDAR-derived intensity metrics and echo categories to delineate tree species. Their results showed that first-returns provided the most information for species classification, single-returns the least information, and last-returns offered additional information. Orka et al. (2010), for two sets of LiDAR data, emphasized that the most important classification features seemed to be normalized heights from the last echoes, density features from the last echoes, and intensity features from the first and last echoes. Different echo categories were affected differently by canopy conditions. Reitberger et al. (2008) found that the mean intensity of laser echoes inside the tree led to a higher classification of species accuracy than the mean intensity of the upper $10 \%$ of the tree crown. Korpela et al. (2010) compared tree species classification based on data from two laser sensors (data sets) with a one-year temporal mismatch using the first-or-only echo intensity features. Their results suggested that leaf size, orientation, and foliage density affect the intensity, therefore making it not affected only by reflectance. In their experiment, intensity normalization improved the classification performance in the data from each sensor (ALTM3100 sensor OA = 83.5\%, improved by 1.8\%; ALS50 OA = 88.5\%, improved by $5.9 \%$ ), as well as in the combined data set (OA $=90.8 \%$, improved by $5.7 \%$ ). Hovi et al. (2016) and Shi et al. (2018) confirmed the results of Korpela et al. (2010) that only returns were informative of tree species and less sensitive to structural differences within the species, compared to the first or single returns. Shi et al. (2018) emphasized that the mean intensity of first or single returns and the mean value of echo width are the most powerful LiDAR metrics for tree species classification, in agreement with the previous studies of Yao et al. (2012), in which the results showed that the mean intensity in the entire tree is the most crucial feature in the leaf-on case and the mean pulse width of single and first reflections in an entire tree segment works better in the leaf-off condition. Vauhkonen et al. (2010), in a study on spruce and pine classification based on laboratory measurements with active hyperspectral LiDAR instrument data, tested whether these species could be separated using combined range and reflectance measurements. The analysis focused on pulses that penetrated through the foliage, improving species classification accuracy with very similar reflectance properties. Vauhkonen et al. (2010) found out that species with highly similar reflectance properties can be better distinguished by analyzing the reflectance values of the types of returns separately.

Most ALS systems use one wavelength scanner, either near-infrared or shortwave infrared. The recently developed technique of Multispectral Laser Scanning (MLS) allows 
for the acquisition of a dense point cloud with additional spectral information of three different wavelength channels: $1550 \mathrm{~nm}, 1064 \mathrm{~nm}$, and $532 \mathrm{~nm}$. As a single-sensor solution, MLS is currently becoming an innovative tool for providing tree-specific valuable information required for forest mapping (i.e., structure and reflectance). Having broader spectral information could simplify the processing of data and facilitate its interpretation. However, the cost of data acquisition with MLS is higher than acquisition with aerial spectral sensors and ALS on the same flight. Nevertheless, it is expected that MLS acquisition costs will decrease as MLS techniques advance [34]. MLS has a great potential for the species classification process, which has been emphasized in many publications $[34,35,76,88]$. Features derived from multispectral ALS data that might be used for species classification are given in Table 3.

Table 3. Multi-channel intensity features derived from LiDAR data.

\begin{tabular}{ll}
\hline Feature & Definition \\
\hline $\mathrm{I}_{\min }^{i}$ & Minimum of intensity of $i$ th channel \\
$\mathrm{I}_{\text {max }}^{i}$ & Maximum of intensity of $i$ th channel \\
$\mathrm{I}_{m}^{i}$ & Mean of intensity of ith channel \\
$\mathrm{I}_{s t d}^{i}$ & Standard deviation of intensity of $i$ th channel \\
$\mathrm{I}_{c v}^{i}$ & Coefficient of variation of intensity of $i$ th channel \\
$\mathrm{I}_{m e d}^{i}$ & Median of intensity of $i$ th channel \\
$\mathrm{I}_{s k}^{i}$ & Skewness of intensity of $i$ th channel \\
$\mathrm{I}_{\text {range }}^{i}$ & Range of intensity of $i$ th channel \\
$\mathrm{I}_{k \text { knt }}^{i}$ & Kurtosis of intensity of $i$ th channel \\
$\mathrm{I}_{10 t o 90}^{i}$ & Percentiles of intensity of $i$ th channel from $10 \%$ to $90 \%$ with $10 \%$ \\
$\mathrm{I}^{1+2+3}, \mathrm{I}^{1+2}, \mathrm{I}^{1+3}, \mathrm{I}^{3+2}$ & increment \\
$\mathrm{I}_{F}^{i} /\left(\mathrm{I}^{1}+\mathrm{I}^{2}+\mathrm{I}^{3}\right)$ & Intensity computed from combined set of echoes from different \\
$\mathrm{I}^{3} / \mathrm{I}^{2}, \mathrm{I}^{3} / \mathrm{I}^{1}, \mathrm{I}^{2} / \mathrm{I}^{1}$ & Rannels \\
$\left(\mathrm{I}^{2}-\mathrm{I}^{3}\right) /\left(\mathrm{I}^{2}+\mathrm{I}^{3}\right)$ & Ratios of intensity features, F refers to different single-channel \\
\hline
\end{tabular}

Yu et al. (2017) performed a study assessing tree classification using a different combinations of features gathered by MLS: point cloud features alone, single-channel intensity features, multi-channel intensity features, point cloud with single-channel intensity features, and all features combined. The highest overall accuracy of $85.9 \%$ for three species classification was generated using point cloud and single-channel intensity features. In contrast, the lowest overall accuracy $(\mathrm{OA}=76.0 \%)$ was produced by point cloud features alone. The results showed that there is no significant difference in classification accuracy while using single-channel features $(\mathrm{OA}=85.42 \%)$, single-channel and point cloud features $(\mathrm{OA}=85.59 \%)$, or all features generated from the three channels $(\mathrm{OA}=85.6 \%)$. This means that the point cloud features did not improve the accuracy of the species classification. Moreover, using multi-channel intensity features $(\mathrm{OA}=81.60 \%)$ for species classification did not provide more information than single-channel intensity features. Yu et al. (2017) emphasized that additional information provided by multispectral laser scanning might be a valuable source of information. Still, as the results above showed, it cannot guarantee higher accuracy of tree classification. In a recent study, Kukkonen et al. (2019) compared the results of three main species classification using MLS with unispectral LiDAR (1064 nm wavelength channel) and showed that multispectral LiDAR obtained better results $(\mathrm{OA}=88.2 \%$, $\kappa=0.79)$ than unispectral $\operatorname{LiDAR}(\mathrm{OA}=85 \%, \kappa=0.72)$. It should be noted that in the study of Kukkonen et al. (2019), multispectral LiDAR predicted broadleaved trees much better $(\mathrm{PA}=51.1 \%)$ than unispectral LiDAR $(\mathrm{PA}=16.8 \%)$. Yu et al. $(2017)$ also confirmed that multi-channel intensity features are powerful while classifying birch (point cloud 
features PA $=45.8 \%$, MLS features in the best scenario PA $=70.99 \%$ ). In the experiment of Kukkonen et al. (2019), pine and spruce prediction for both multispectral and unispectral LiDAR was comparable. Kukkonen et al. (2019) also compared the results of three main species classification using multispectral LiDAR and unispectral LiDAR with 4-band aerial images collected at a different times. Their results showed that the overall accuracy of the classification performed on fused unispectral LiDAR data with aerial imaging is comparable to the overall accuracy of species classification performed on multispectral LiDAR data. Krüger geb. Amiri et al. (2018) simulated an MLS sensor by combining two different LiDAR sensors providing three wavelength channels and marked that the third spectral channel $(532 \mathrm{~nm})$ did not have any meaningful effect for tree species classification. Budei et al. (2017) examined discrete-return MLS data for identifying species and concluded that species identification accuracy could be improved by using MLS, mostly when the number of species classes is relatively high (seven or more species).

LiDAR intensity data contain plenty of information about different forest tree species. Unfortunately, it still has some limitations for tree species with similar canopy reflectances. Some of the reviewed publications have presented that the combination of intensity and height metrics could lead to complementary advantages in tree species classification, thus generating better results $[34,76,79,80,83,86]$.

\subsubsection{Full-Waveform Metrics}

Some studies have demonstrated the high potential of full-waveform data for tree species classification by applying a set of LiDAR full-waveform features $[4,36,37,60,84]$. In general, full-waveform LiDAR systems sample and record the entire backscattered signal intensity at regular time intervals, unlike discrete-return LiDAR systems. To normalize information and decrease sources of errors in further processing steps, pre-processing of the signal is used. A cross-section profile can be directly derived from the recorded waveform and mapped into 3D data using deconvolution techniques. Extraction of detection peaks from the waveform can be also performed with a decomposition algorithm $[89,90]$. The most commonly used method is Gaussian decomposition, which is used to fit a generalized Gaussian function, according to the Levenberg-Marquardt algorithm [90]. Metrics that can be derived from the full waveform include, among others, the height of median energy, waveform extent, waveform distance, number of peaks, roughness of the outermost canopy, front slope angle, and return waveform energy [91-93]. All these metrics have physical explanations; for instance, waveform extent relates to maximum tree height, while return waveform energy describes the canopy surface characteristics. Features that might be derived from full-waveform decomposition for species classification are given in Table 4 .

Table 4. Single waveform LiDAR metrics.

\begin{tabular}{|c|c|}
\hline Feature & Definition \\
\hline WD & $\begin{array}{l}\text { Waveform distance-distance between waveform begin and the ground (last } \\
\text { peak) }\end{array}$ \\
\hline WE & Waveform extent-distance between waveform begin and end \\
\hline HOME & $\begin{array}{l}\text { Height of median energy-distance from waveform centroid to the ground } \\
\text { (last peak) }\end{array}$ \\
\hline HTRT & Height of median energy / canopy height ratio \\
\hline FS & $\begin{array}{l}\text { Front slope angle-vertical angle from waveform begin to the first peak of } \\
\text { canopy return energy }\end{array}$ \\
\hline NP & $\begin{array}{l}\text { Number of peaks-number of detected peaks within each normalized com- } \\
\text { posite waveform }\end{array}$ \\
\hline $\mathrm{H}_{x}$ & $\begin{array}{l}x \% \text { quartile height from } 25 \% \text { to } 100 \% \text { with } 25 \% \text { increment-elevation at } x \% \\
\text { of the returned energy subtracted by the ground elevation }\end{array}$ \\
\hline ROUGH & $\begin{array}{l}\text { Roughness of outer canopy-distance from the waveform beginning to the } \\
\text { first peak }\end{array}$ \\
\hline
\end{tabular}


Table 4. Cont.

\begin{tabular}{ll}
\hline Feature & Definition \\
\hline RWE & $\begin{array}{l}\text { Return waveform energy-the area below the waveform between beginning } \\
\text { and end }\end{array}$ \\
GE & $\begin{array}{l}\text { Ground energy-total intensity of the last mode } \\
\text { CE }\end{array}$ \\
$\begin{array}{l}\text { Canopy energy-difference between return waveform energy and ground } \\
\text { return energy }\end{array}$ \\
GRND & Ground return ratio-ground return energy divided by canopy return energy \\
\hline
\end{tabular}

Hovi et al. (2016) studied four LiDAR data sets acquired within 4 years for the classification of three species and concluded that waveform features outperformed the discretereturn intensity data $(\mathrm{OA}=74-85 \%, \kappa=0.57-0.75$ vs. $\mathrm{OA}=84-91 \%, \kappa=0.74-0.86$ for manually extracted trees; $\mathrm{OA}=78-89 \%, \kappa=0.64-0.82$ vs. OA $=88-95 \%, \kappa=0.79-0.91$ for trees extracted by watershed segmentation). Improvements in this experiment were ascribed to the total backscattered energy feature. Reitberger et al. (2008) presented an approach for the decomposition of full-waveform data, using full-waveform features for the classification of deciduous and coniferous trees. The full-waveform decomposition provides additional attributes for the detected points, such as the intensity and pulse width, which improved the classification results in general. Additionally, full-waveform decomposition provided increased spatial point density, which allowed the internal tree structure to be highly resolved. With the proposed approach, an OA $=85.4 \%$ of classification was generated in leaf-on condition, while $\mathrm{OA}=95.7 \%$ was obtained in leaf-off condition. In the study of Reitberger et al. (2008), the pulse width turned out to be the feature that provided the best result in the leaf-on case. Yao et al. (2012) demonstrated the usefulness of full-waveform features for tree segmentation and species classification of deciduous and coniferous trees, achieving OA =95\%. Heinzel and Koch (2011) found that the most important full-waveform parameter for species delineation was the mean intensity (singular reflections have the highest impact), the median of the width, and the mean total number of targets within a beam (all reflections). Heinzel and Koch (2012) investigated five multiple data sources (full-waveform, height, texture, hyperspectral, and CIR metrics) and showed that features derived from full-waveform data generated the highest classification accuracy $(\mathrm{OA}=79.22 \%)$ for four species. In contrast, LiDAR features generated one of the lowest overall accuracies $(\mathrm{OA}=47.27 \%)$. Their experiment showed that using combined features from all groups for species classification generated the greatest overall accuracy $(\mathrm{OA}=88.03 \%)$. The combination of full-waveform backscattering properties with other metrics has a high potential for tree species classification, which has also been emphasized in other studies [81,94]. Yu et al. (2014) compared the results of three tree species classification using low-density LiDAR data (average $1 \mathrm{pulse} / \mathrm{m}^{2}$ ) obtained with full-waveform features for the classification, discrete-return features, and a combination of those features. The best overall classification accuracy $(\mathrm{OA}=73.4 \%)$ was generated when full-waveform features were included in the classification with features of discrete-return. Classification with solely full-waveform features developed OA $=71.5 \%$, while only discrete-return features developed $\mathrm{OA}=62.1 \%$. The results suggested that full-waveform LiDAR data contains more information about structural and physical properties. Zhou et al. (2018) [95] investigated the capacity of full-waveform LiDAR data for species identification through the integration of waveform metrics with random forest and conditional inference forest methods and Bayesian multinomial logistic regression. Their experiment showed that composite waveforms are more informative than raw waveforms and waveform-based point clouds for characterizing tree species in the study area. Cao et al. (2016) indicated that full-waveform LIDAR data have significant potential for classifying tree species in subtropical forests. In their study, full-waveform metrics were extracted using a voxel-based composite waveform approach and tested to distinguish species at three levels of discrimination. The applied approach ensured a relatively high 
accuracy of species classification: $\mathrm{OA}=68.6 \%$ for six species, $\mathrm{OA}=75.8 \%$ for the four main species, and $\mathrm{OA}=86.2 \%$ for conifers and deciduous trees. Full-waveform metrics, based on the height of median energy, waveform distance, and several waveform peaks, showed high classification importance and were stable across various voxel sizes. The obtained results indicated that voxel-based approaches can alleviate some of the problems associated with large scanning angles. Blomley et al. (2017) presented a novel methodology to derive features for tree species classification by capturing the geometric distribution of laser scanning returns or their waveform attributes. The spin image algorithm used in this approach relies on spinning the image plane around a specific axis, collecting the number of LiDAR returns or mean values of returns attributes per pixel as respective values. The results showed that the used approach improved the classification of three species in almost all test cases for two waveform LiDAR data sets that differed in footprint size, pulse width, density, and laser wavelength. Although the basic classification accuracy given by the non-spatial metrics was very high $(\mathrm{OA}=90.1 \%$ for the LMS-Q680i data set, OA $=90.5 \%$ for the ALS60 data set), the overall improvement in the combined case of a spin image with non-spatial metrics was equal to $1.1 \%$ for LMS-Q680i data and 2.0\% for ALS60 data.

All studies presented above demonstrated the great potential of tree species classification based on data from full-waveform LiDAR. It has been confirmed that attributes and metrics derived from full-waveform data can improve tree species classification performance, compared to the species classification based on geometric or radiometric features, or their combination.

\subsection{Seasonal Tree Condition}

Tree species classification in all reviewed studies was carried out based on LiDAR data acquired under leaf-on condition [60,81], leaf-off condition [94,96], or under both conditions $[37,61,84,86]$. Seasonal changes in canopy leaf conditions influence the physical structure of the vegetation and impact the penetration and concentration of ALS pulses near the top of the canopy [97]. In some of reviewed studies, the authors concluded that the leafoff data set produced higher species classification accuracy than the leaf-on data set [84-86]. Reitberger et al. (2008), for broadleaved and coniferous species classification, obtained $\mathrm{OA}=95.7 \%$ for leaf-off condition, while the leaf-on condition LiDAR data generated $\mathrm{OA}=85.4 \%$. In this study, the classification of deciduous trees worked better in leaf-off condition. Kim et al. (2009), for eight broadleaved species and seven coniferous species, obtained better results on the leaf-off data set, similar to Reitberger et al. (2008), with leaf-off $\mathrm{OA}=83.4 \%$, while on the leaf-on data set gave OA $=73.1 \%$. Shi (2018) reported only a slight improvement in classification accuracy when using leaf-off data, compared to leaf-on data. However, in the study of Shi et al. (2018), there was no statistically significant difference in species classification accuracy between leaf-on and leaf-off LiDAR features. The combination of features of both data sets significantly increased the overall accuracy of species classification from $\mathrm{OA}=58.2 \%$ (leaf-on) and $\mathrm{OA}=62.0 \%$ (leaf-off) to $\mathrm{OA}=66.5 \%$ [86]. Other studies have confirmed that the integration of LiDAR data acquired in two seasons under leaf-on and leaf-off conditions improves tree classification $[61,85]$. Sumnall et al. (2015) [98] concluded that both leaf-on and leaf-off data benefit greater complementary information about the forest canopy profile than discrete-return or fullwaveform LiDAR data.

In summary, data acquisition in the leaf-off condition offers a higher potential for representing the tree crown structure using radiometric features. All internal structure metrics are more efficiently used for species classification when there is no foliage cover-the dense canopy under leaf-on conditions fully intercepts the laser beam in the crown. It causes a lower proportion of returns interacting with understory vegetation. The leaf-off condition produces more intermediate returns, which provides more information of the vertical tree structure, driving an improvement in the accuracy of species discrimination $[61,81,86,97]$. The combination of the two data sets of leaf-on and leaf-off conditions can increase the overall accuracy of tree classification. 


\subsection{Classification Algorithms}

In recent years, machine learning techniques, due to the accuracy of the produced classifications, have received increasing interest and gained popularity in many applications. Machine learning classifiers are algorithms that allow for the prediction of a class of input data based on specific methods built into the algorithms based on the use of training data. Combining machine learning techniques with remote sensing data creates possibilities for solving complex problems, such as tree species classification [61].

All machine learning algorithms can be divided into three classes: classification tree methods (e.g., decision trees, Random Forest-RF), grouping and separability methods (e.g., Support Vector Machine-SVM, k-nearest neighbors- kNN), and rule creation and application methods (Convolutional Neural Network-CNN) [61]. Species classification based on remote sensing data has evolved along with the methodological developments of statistical learning. In the reviewed studies, the following species classifiers have been applied: logistic regression [35,43,66], linear discriminant analysis [43,75,80,87], and kNN [43,66], with the most popular methods recently being random forest $[3,34,43,61,64,81,88,99-101]$ and support vector machines $[3,5,61,66,87,101-104]$.

\subsubsection{Decision Trees and Random Forest}

Decision trees are effective tools for prediction and are the most widely used methods for supervised learning. Decision tree algorithms identify ways to split a set of data based on every feature of the data set. The model obtains nodes-locations where the tree splits, according to the value of some features-and edges-the outcome of a split to the next node. Building a decision tree and specifying features that split the data might be challenging. This is why many decision trees use a randomly selected, independently sampled feature at every single split; this is called the Random Forest technique. It has been noted that random inputs and random features produce good results in classification with the random forest method [105].

\subsubsection{Support Vector Machine}

Support vector machine is a non-linear classification supervised machine learning model, which analyzes data and recognizes patterns. An SVM uses geometry to make a categorical prediction: it classifies input variables by finding an optimal separating hyperplane that maximizes the margin width between categories in a data set. The training points near the hyperplane are called support vectors. Support vector machines can be used for regression and classification analysis [106].

Nguyen et al. (2019) performed a weighted SVM (WSVM) classifier for tree species recognition using data from ALS as a strategy to correct the loss of SVM performancedependent distribution of tree species and the presence of unreliable data due to inaccurate positions of field data and errors in tree extraction. The WSVM classifier extracts and uses species weights and sample weights (i.e., high weights and reduced weights), as importance is defined based on a strategy that relies on the distribution of unlabeled samples in the feature space. Their experimental results showed an improved classification accuracy of minority classes: WSVM provided $2.4 \%$ higher OA and $3.9 \%$ higher $\kappa$ coefficient, compared to traditional SVM.

\section{Results}

In this paper, we review publications investigating tree species classification performed on ALS data with particular emphasis on LiDAR-derived features used for classification. The reviewed studies were categorized into three LiDAR-derived metric groups, which were used for species classification:

- geometry (G) - geometric features: statistics, point distribution, vertical profile, shape;

- intensity+ (I+) - radiometric features, intensity metrics combined with geometric features, intensity features from three Multispectral Laser Scanning channels; 
- waveform (WF)—features extracted from the full-waveform decomposition, full-waveform metrics combined with other metrics.

All generated results from the reviewed publications, along with information about the number of discriminated species and the calculated NOCAI, are listed in Table A1 in Appendix A, for studies where geometry features were assessed for species classification; Table A2 for the intensity+ features group; and Table A3 for the waveform features group.

Most of the studies were conducted for the classification of three species (39 cases), followed by studies for two species (21 cases), four species (18 cases), six species (10 cases), and five species ( 5 cases). The classification results of seven, nine, and 15 species were conducted only in one publication each. The number of publications and studies grouped by the number of discriminated species is presented in Figure 1.

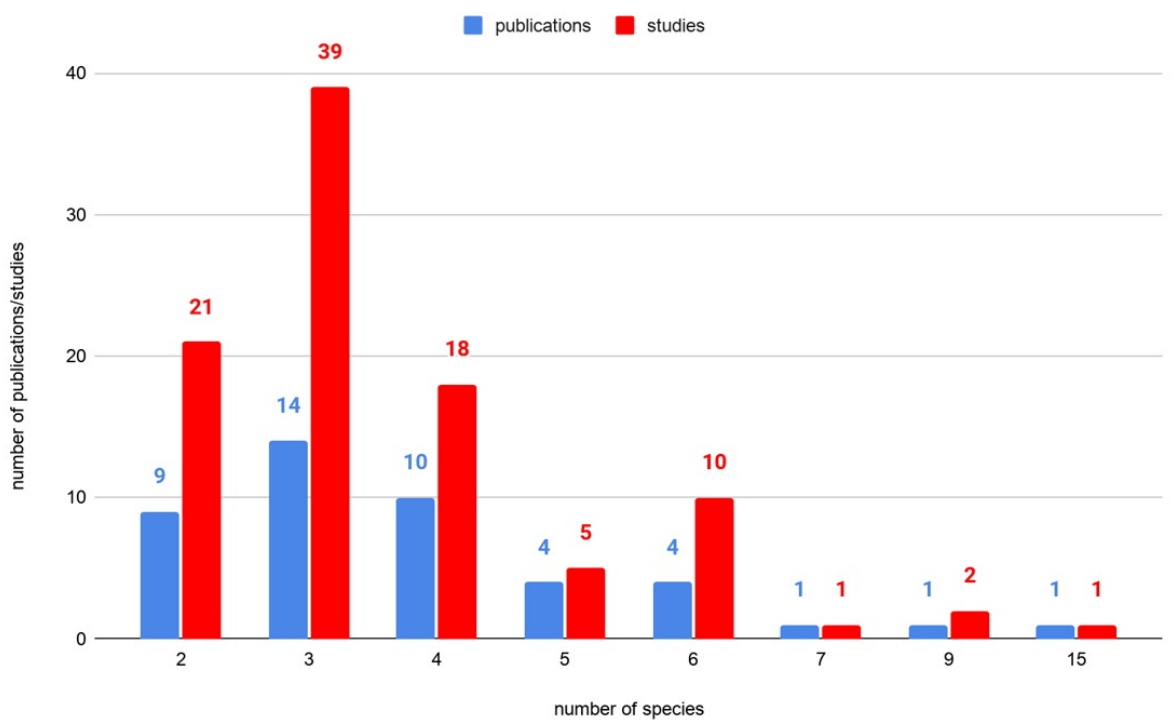

Figure 1. Number of reviewed publications and studies for specified numbers of classified species.

\subsection{Effectiveness of the Features Groups in Species Classification}

Of the reviewed publications, 39 studies were conducted equally for species classification using intensity + features and waveform features, while only 19 studies were conducted on geometry features solely. The number of conducted studies, with their division into feature groups used to classify a specified number of discriminated species, is presented in Figure 2 . The most common studies were processed to classify three species using intensity+ features (18 cases) and waveform features (15 cases).

It should be noted that in general, the overall accuracy of species classification can be influenced by many factors, such as LiDAR data density, season of acquisition, number of discriminated species, approaches for tree delineation from the point cloud, sampling situations, features taken for the classification process, and so on. In this paper, the overall accuracies of all reviewed studies were compared only based on the number of discriminated species and the feature group that was taken for the species classification. Figure 3 presents the relationship between the overall accuracy and the number of classified species for studies where two, three, four, or six species were classified. Results for five, seven, nine, and 15 species were excluded, due to not being representative for statistical analysis. The overall accuracy of species classification declined with the number of classified species. This was similar to the relationship between NOCAI and the number of species, which is presented in Figure 4. 


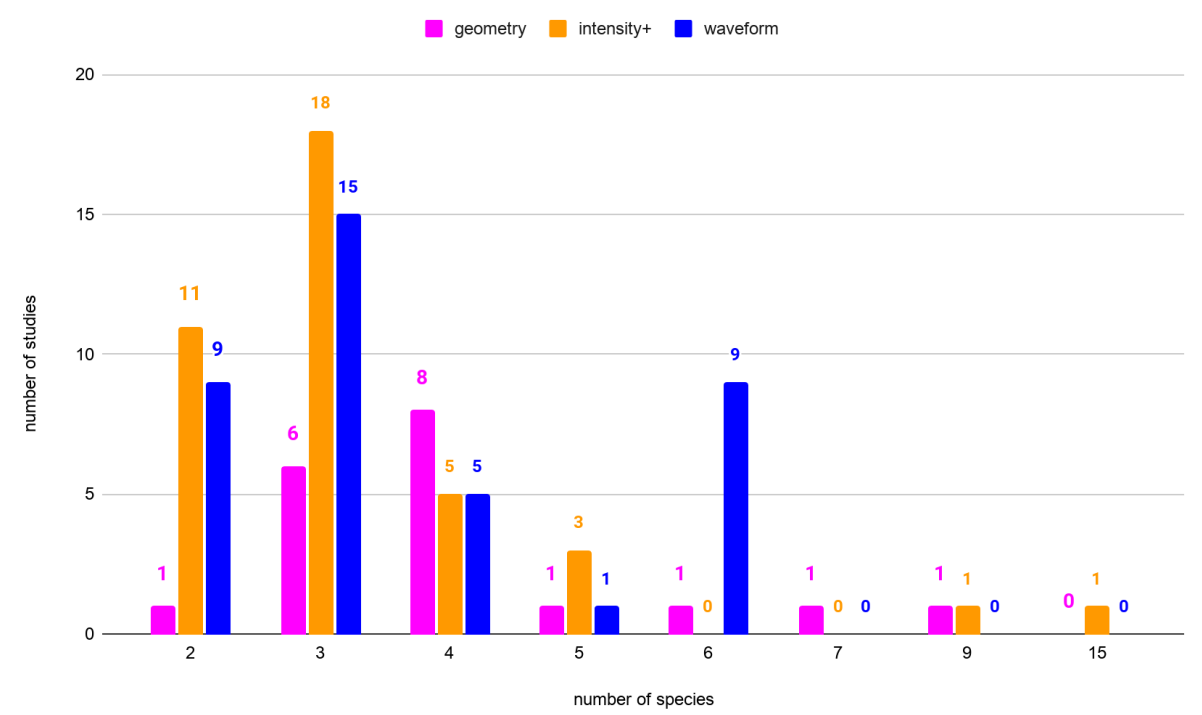

Figure 2. The number of conducted studies with division into feature groups (geometry, intensity+, waveform) used to classify a specified number of species.

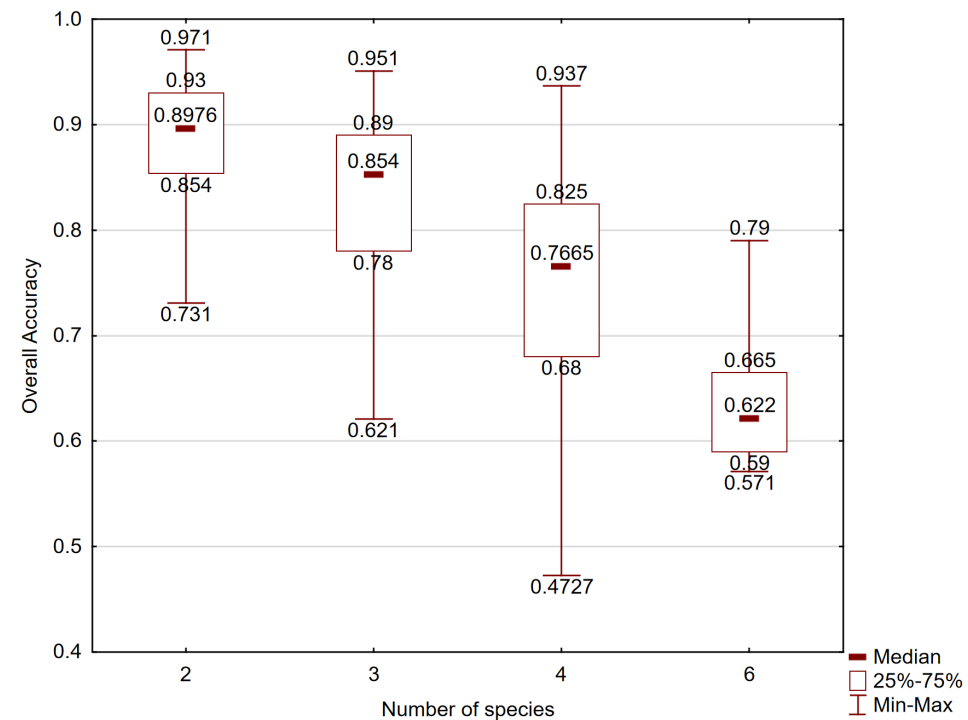

Figure 3. Relationship between the overall accuracy and number of discriminated species in the reviewed studies.

Studies with overall accuracy more significant than the median overall accuracy of all studies for a discriminated number of species $(2,3,4$, and 6 species) are listed in Table A4. Table A4 includes a description of which quartile the result of the study belonged to: QM-U represents the range from the median to upper quartile (75\%), while QU-UW represents the range from upper quartile (75\%) to the upper whisker. By the analysis of the number of these studies, it was observed that the most numerous studies were those in which the waveform feature group was used for species discrimination (see Figure 5). Investigations proceeded with metrics from the full-waveform decomposition were useful for tree species classification (10 cases in QM-U, 12 cases in QU-UW). The waveform group metrics were followed by the intensity+ group (7 cases in QM-U, 6 cases in QU-UW) and geometry group (4 cases in QM-U, 6 cases in QU-UW), respectively. 


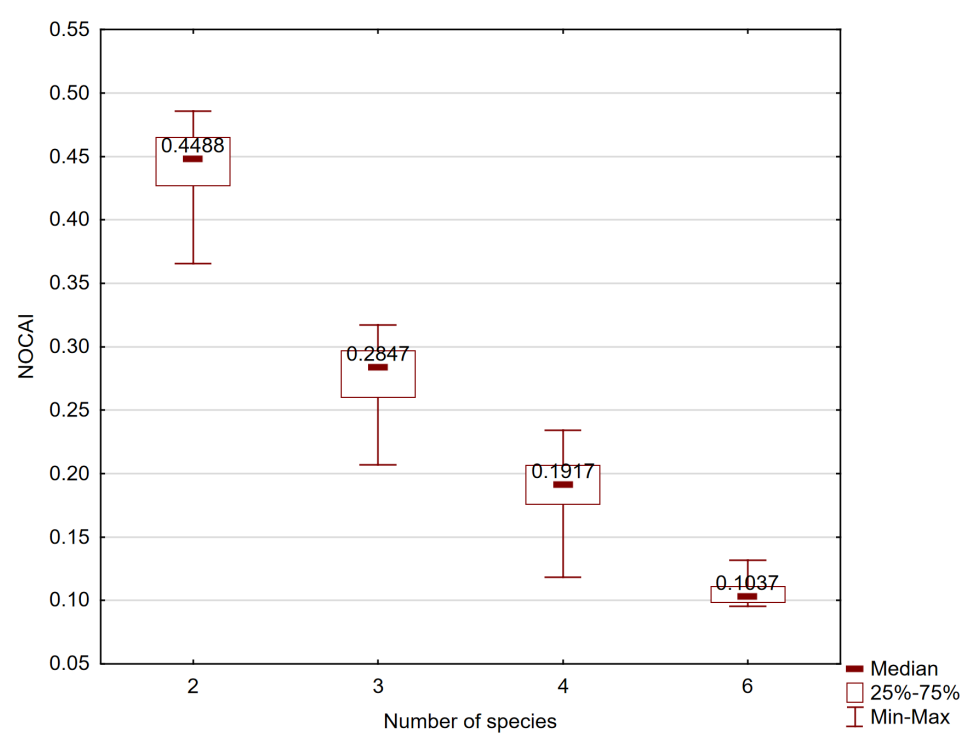

Figure 4. Relationship between NOCAI and the number of discriminated species in the reviewed studies.

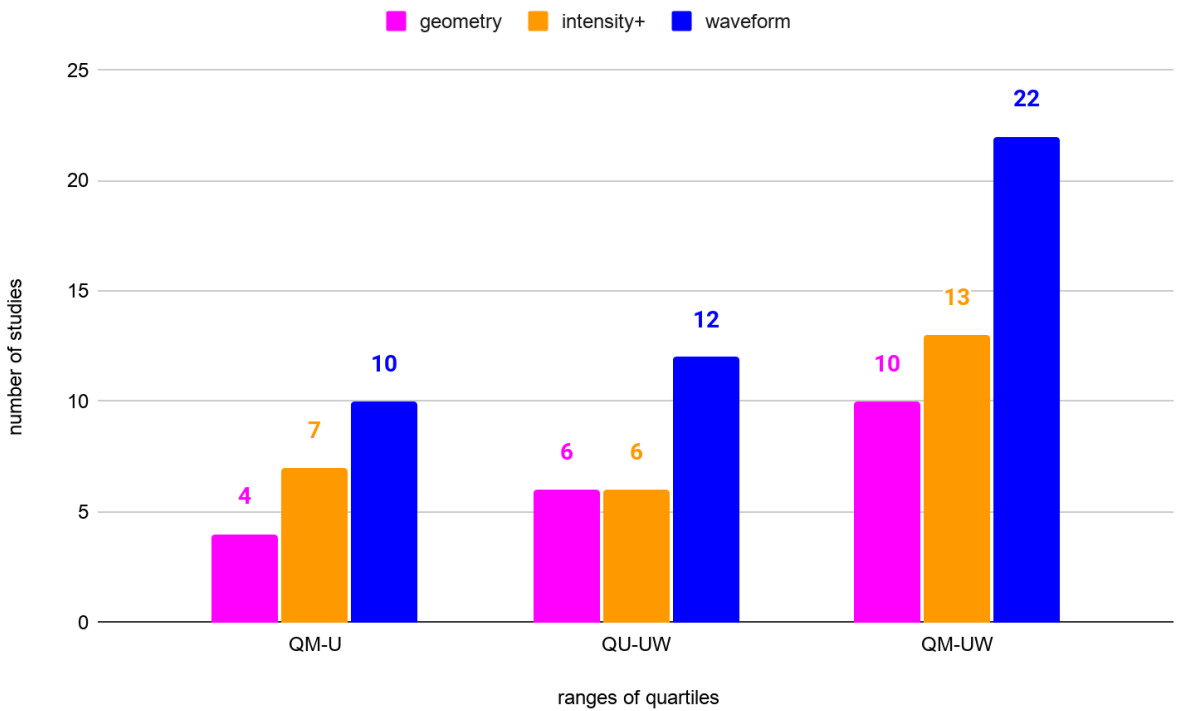

Figure 5. The number of studies with OA higher than median OA, grouped by feature groups (geometry, intensity+, waveform) used for classification with a division into the range of quartiles; QM-U—the range from the median to upper quartile, QU-U—the range from the upper quartile to the upper whisker, and QM-UW—-the range from the median to the upper whisker.

To compare the overall accuracy of classification generated when using the different feature groups, the most relevant studies of three species classification with calculated $\kappa$ coefficient were analyzed. Figure 6 presents a comparison of the classification accuracy using the overall accuracy, $\kappa$ coefficient, and NOCAI for the two most relevant studies of every feature group. Species classification using full-waveform features seemed to generate better results in general $(\mathrm{OA}=95.0-95.1 \%, \kappa=0.91-0.912, \mathrm{NOCAI}=31.67-31.70 \%)$ than geometry features $(\mathrm{OA}=76.04-86.3 \%, \kappa=0.84-0.82, \mathrm{NOCAI}=25.35-28.77 \%)$ and intensity features or their combination $(\mathrm{OA}=90.80-89.00 \%, \kappa=0.57-0.759, \mathrm{NOCAI}=29.67-30.27 \%)$, corresponding to the previous conclusion. It should be emphasized that the intensity+ group features also produced high accuracy in species discrimination. 


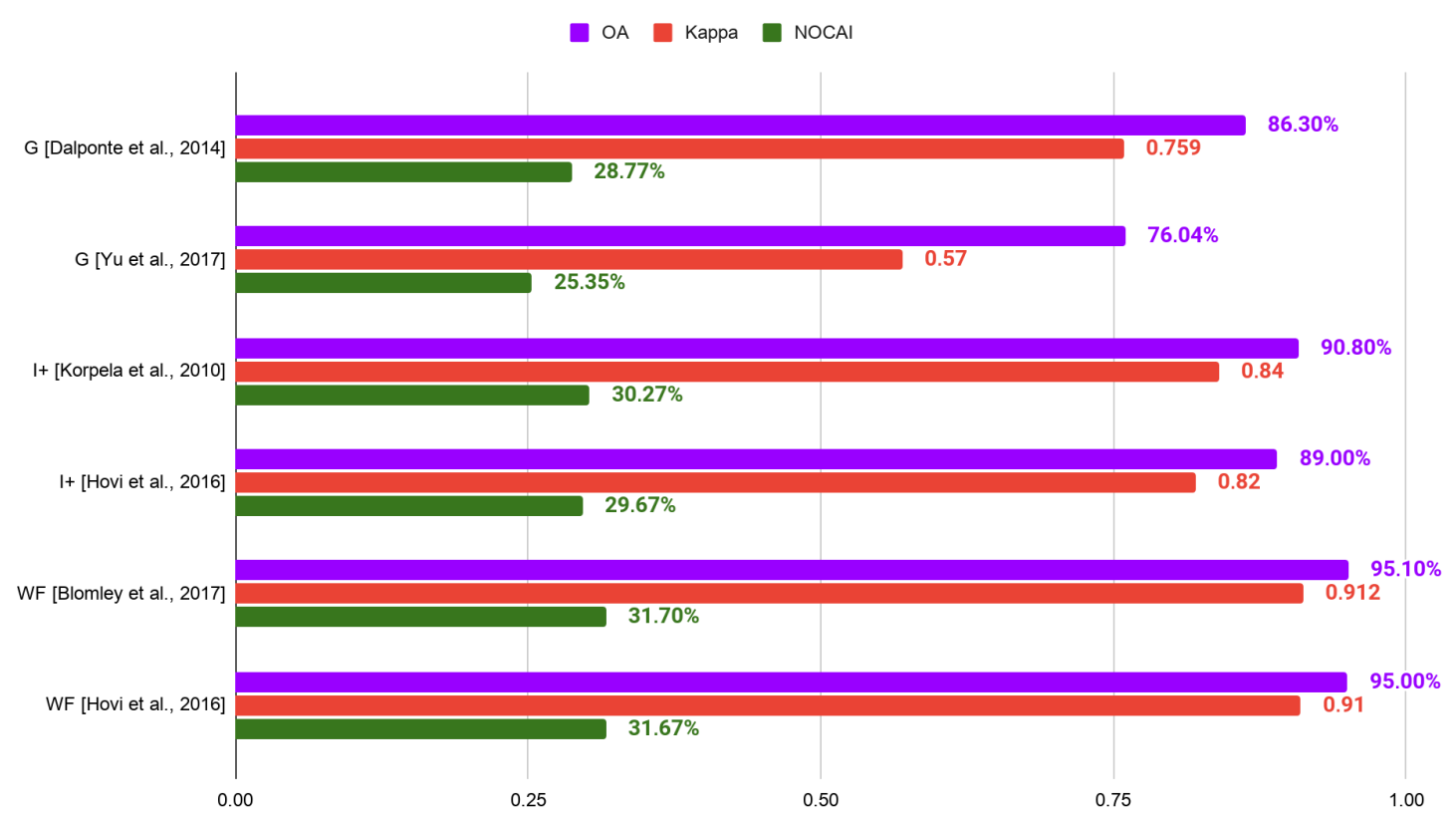

Figure 6. Classification accuracy using overall accuracy, $\kappa$ coefficient, and NOCAI value of the studies where three tree species were classified with feature group; G-geometry group, I+—intensity+ group, WF-waveform group; the studies of classification results are presented in the square bracket.

\subsection{Effectiveness of the Classifiers in Species Classification}

In several of the reviewed studies, tree species classification was carried out using more than one classifier under each scheme to examine the performance of classifiers. Table 5 presents a list of publications with overall accuracy and $\kappa$ coefficient generated by the following classifiers: k-NN, LDA, LR (Logistic Regression), MLC (Maximum-Likelihood Classifier), RF, SVM, and DL (Deep Learning methods).

Based on the reviewed publication results, random forest and support vector machine classifiers generated the highest overall accuracy for species classification, compared to other classifiers, while the differences in RF and SVM results can be treated as marginal [61,67]. Nevertheless, in some of the studies, the SVM classifier has been proved to be more effective in tree species discrimination than other classifiers $[3,66,87,101]$. Despite the high accuracy that random forest and support vector machine methods might generate, it should be emphasized that using a particular classifier always has advantages and disadvantages. Followed by Fassnacht et al. (2016), with a non-parametric SVM approach, no distribution assumption is required and, so, it is appropriate when incorporating non-remote sensing variables into the classification for robustness to noise and rapid prediction of high-dimensional data, where relatively few training data are needed; meanwhile, the optimal design of multi-class SVM is demanding. There is a relatively high computational cost for training due to its algorithmic complexity. For random forest, no distribution assumption is required, the classifier is less sensitive to the number of input variables and overfitting, and there is an intuitive derivation of the accuracy and importance of the variable. At the same time, it may be overfitted in the presence of noisy data and may be biased in the case of response classes that have a different number of levels [107]. Fassnacht et al. (2016) emphasized that from the experience of the authors of their review, the choice of the classifier itself is often of low importance if the data is adequately preprocessed to match the requirements of the classifier. 
Table 5. List of reviewed studies where more than one classifier was used for tree species classification; results are presented as overall accuracy and $\kappa$ coefficient (if calculated); k-NN-k-Nearest Neighbors, LDA-Linear Discriminant Analysis, LR—Logistic Regression, MLC—Maximum-Likelihood classifier, RF—Random Forest, SVM—Support Machine Vectors, DL-Deep Learning methods.

\begin{tabular}{|c|c|c|c|c|c|c|c|}
\hline Article & kNN & LDA & LR & MLC & RF & SVM & DL \\
\hline$[61]$ & & & & & $83.1 \% \mathrm{~N} / \mathrm{A}$ & $82.0 \% \mathrm{~N} / \mathrm{A}$ & \\
\hline \multirow[t]{7}{*}{ [43] } & $73.4 \% 0.639$ & $77.1 \% 0.628$ & & & $81.7 \% 0.690$ & & \\
\hline & $76.0 \% 0.681$ & $78.9 \% 0.656$ & & & $83.5 \% 0.720$ & & \\
\hline & $78.4 \% 0.644$ & $79.6 \% 0.664$ & & & $82.6 \% 0.706$ & & \\
\hline & $85.1 \% 0.774$ & $87.4 \% 0.785$ & & & $88.5 \% 0.804$ & & \\
\hline & $83.1 \% 0.715$ & $82.2 \% 0.703$ & & & $85.1 \% 0.750$ & & \\
\hline & $89.0 \% 0.816$ & $88.5 \% 0.805$ & & & $89.3 \% 0.819$ & & \\
\hline & $89.4 \% 0.840$ & $90.0 \% 0.830$ & & & $90.8 \% 0.844$ & & \\
\hline \multirow[t]{3}{*}{ [87] } & & $83.2 \% \mathrm{~N} / \mathrm{A}$ & & & & $88.6 \% \mathrm{~N} / \mathrm{A}$ & \\
\hline & & $74.6 \% \mathrm{~N} / \mathrm{A}$ & & & & $75.4 \% \mathrm{~N} / \mathrm{A}$ & \\
\hline & & $86.4 \% \mathrm{~N} / \mathrm{A}$ & & & & $892.8 \% \mathrm{~N} / \mathrm{A}$ & \\
\hline [65] & & & & & & $60.3 \% 0.476$ & $62.3 \% 0.513$ \\
\hline \multirow[t]{2}{*}{ [66] } & $83.6 \% 0.780$ & & $86.7 \% 0.822$ & $84.7 \% 0.79$ & & $89.7 \% 0.863$ & \\
\hline & $49.0 \% 0.377$ & & $47.3 \% 0.364$ & $46.3 \% 0.351$ & & $50.5 \% 0.393$ & \\
\hline \multirow[t]{2}{*}{ [67] } & & & & & $79 \% 0.75$ & $79 \% 0.74$ & \\
\hline & & & & & $78 \% 0.73$ & $78 \% 0.74$ & \\
\hline
\end{tabular}

\section{Conclusions and Discussion}

In this paper, we reviewed publications investigating tree species classification performed on airborne laser scanning data, with particular emphasis on studies where LiDARderived features were used for the classification. In total, 44 publications including tree species classification were reviewed, for a total of 97 performed studies. All reviewed studies were categorized into the three metric groups used for species discrimination: geometry (geometric features), intensity+ (radiometric features, intensity metrics combined with geometric features, intensity features from three Multispectral Laser Scanning channels), and waveform (features extracted from the full-waveform decomposition, full-waveform metrics combined with other metrics). It was observed that the most numerous studies with high overall accuracy (greater than the median overall accuracy of the studies) were those in which the waveform feature group was used for species discrimination. This corresponds to the conclusion that full-waveform data have great potential in the tree species classification process $[4,36,37,60,84]$. The benefit of full-waveform features is derived from the available waveform information, which can be directly accessed or derived by further processing. Additionally, it has a higher point density and a theoretically unlimited number of recorded returns for each emitted pulse [73]. It should be emphasized that radiometric features (intensity+ group) also generated high accuracy. Radiometric features seem to be useful and very promising features in the tree species classification process, as also demonstrated in many studies $[36,74,75,83,84]$. Moreover, the combination of radiometric features with LiDAR height information could lead to achieving the complementary advantages of the different information needed in the species classification process to improve the overall accuracy $[34,76,79,80,83,86]$. In this paper, studies where species classification was carried out by more than one classifier under each scheme were reviewed, to examine the performance of particular classifiers. Based on the gathered results, the random forest and support vector machine classifiers generated the highest overall accuracy for species classification. In some studies, the SVM classifier has been proved to be more effective in tree species discrimination than other classifiers $[3,66,87,101]$; however, in other studies, the differences between RF and SVM results were marginal [61,67]. Unfortunately, a specific group of features dedicated to species classification and the particular classifiers used for the classification do not guarantee a high overall accuracy. Employing multiple features for species classification is required to increase the discrimination accuracy. It is recommended to exploit more features, especially using data fusion of active and passive 
optical systems, which is in common with the observed trend of an increasing number of studies with the usage of more than one sensor type data for species classification [107]. LiDAR technology, which is valued for its unique capabilities for detecting 3D structural information, is a great supplement to discrimination based on any optical remote-sensed imagery. It has been proven, in many publications, that the combination of LiDAR data with multispectral or hyperspectral imagery generates greater species classification accuracy than LiDAR data alone $[42,59,62-68]$. LiDAR data also complements imagery data used for other purposes, such as mapping dead trees with crowns and snags (dead trees without crowns) [108,109], analyzing forest structural complexity [110,111], and determining bird species habitats [112], where passive imagery alone would not be as efficient as a set fused with LiDAR data. Fusion of data from different sensors deserves a great attention, as it is a valuable data set to provide sophisticated analysis and get satisfactory results. Although multispectral, hyperspectral, and LiDAR data provide complementary information, the integration of these data into an information extraction procedure can be challenging. Nevertheless, combining remote sensing data-derived features and machine learning techniques creates possibilities for solving complex problems, such as tree classification [61]. Although there are multiple features, different classifiers could be considered simultaneously by exploiting the best processing chain for each specific tree class. Improvement of accuracy of individual tree extraction and the optimization of feature selection for discrimination could lead to higher classification accuracy.

Apart from all the algorithms and methods used in tree classification procedures, the technological development of sensors plays an important role. As the technical parameters of the equipment increase, it will become possible to obtain more accurate data and more powerful sensor-derived metrics; thus, the classification results could be more accurately determined. In terms of classification algorithms, the fastest development has been predicted for artificial intelligence-related algorithms; we have already seen their application in tree classification. Future research should put more effort into the investigation of species-specific feature characteristics and detailed analyses of the impacts of technical factors, tree extraction methods, and various growing conditions on the feature characteristics. Additionally, for different types of forests, simplified data sets combining the most powerful significant tree species characteristics from different sensors could be examined and developed. Approaches and algorithms that fuse different remote sensing data sets in a more profound way should be developed, as multiple sources of remote sensing data should be included in the classification attempts.

Author Contributions: Conceptualization, J.R. and M.M.; investigation, M.M.; Writing-Original draft preparation, M.M.; Writing-Review and editing, M.M. and J.R.; visualization, M.M.; supervision, J.R.; project administration, J.R. All authors have read and agreed to the published version of the manuscript.

Funding: This research was funded by Ministerstwo Nauki i Szkolnictwa Wyższego (Ministry of Science and Higher Education), Republic of Poland, under the program entilted "Doktorat wdrożeniowy" (Industrial Doctoral Program) [DWD/3/19/2019].

Institutional Review Board Statement: Not applicable.

Informed Consent Statement: Not applicable.

Data Availability Statement: Data sharing not applicable.

Conflicts of Interest: The authors declare no conflict of interest.

\title{
Abbreviations
}

\author{
ABA Area-Based Approach \\ ALS Airborne Laser Scanning \\ CHM Canopy Height Model
}




$\begin{array}{ll}\text { CNN } & \text { Convolutional Neural Network } \\ \text { DL } & \text { Deep learning } \\ \text { G } & \text { geometry features group } \\ \text { GPS } & \text { Global Positioning System } \\ \text { I+ } & \text { radiometric features group } \\ \text { IMU } & \text { Inertial Measurement Unit } \\ \text { ITC } & \text { Individual Tree Crown } \\ \text { kNN } & \text { k-nearest neighbors } \\ \text { LiDAR } & \text { Light Detection and Ranging } \\ \text { LR } & \text { Logistic Regression } \\ \text { MLC } & \text { Maximum-Likelihood Classifier } \\ \text { MLS } & \text { Multispectral Laser Scanning } \\ \text { NOCAI } & \text { Number of Categories Adapted Index } \\ \text { OA } & \text { Overall Accuracy } \\ \text { QM-U } & \text { quartile range from the median to upper quartile (75\%) } \\ \text { QM-UW } & \text { quartile range from the median to the upper whisker } \\ \text { QU-UW } & \text { quartile range from upper quartile (75\%) to the upper whisker } \\ \text { PA } & \text { Producer's Accuracy } \\ \text { RF } & \text { Random Forest } \\ \text { RS } & \text { Remote Sensing } \\ \text { SVM } & \text { Support Vector Machine } \\ \text { TLS } & \text { Terrestrial Laser Scanning } \\ \text { UAV } & \text { Unmanned Aerial Vehicle } \\ \text { WF } & \text { full-waveform features group } \\ \text { WSVM } & \text { Weighted Support Vector Machine } \\ \text { 2D } & \text { two-dimensional } \\ \text { 3D } & \text { three-dimensional } \\ & \end{array}$

\section{Appendix A}

Table A1. List of results of reviewed studies where species classification was performed with a geometry feature group; list sorted by species number and overall accuracy; DM-additional information for studies where trees were delineated manually.

\begin{tabular}{ccccc}
\hline Number of Species & OA & $\kappa$ & NOCAI & Article \\
\hline 2 & $95.0 \%$ & N/A & $47.50 \%$ & {$[75]$} \\
3 & $88.6 \%$ & N/A & $29.53 \%$ & {$[87]$} \\
3 & $86.3 \%$ & 0.759 & $28.77 \%$ & {$[63]$} \\
3 & $85.4 \%(\mathrm{DM})$ & 0.739 & $28.47 \%$ & {$[63]$} \\
3 & $83.15 \%(\mathrm{DM})$ & $\mathrm{N} / \mathrm{A}$ & $27.72 \%$ & {$[61]$} \\
3 & $76.04 \%$ & 0.57 & $25.35 \%$ & {$[34]$} \\
3 & $62.1 \%$ & $\mathrm{~N} / \mathrm{A}$ & $20.70 \%$ & {$[81]$} \\
4 & $93.7 \%$ & $\mathrm{~N} / \mathrm{A}$ & $23.43 \%$ & {$[78]$} \\
4 & $89.7 \%$ & 0.86 & $22.43 \%$ & {$[66]$} \\
4 & $85 \%$ & $\mathrm{~N} / \mathrm{A}$ & $21.25 \%$ & {$[79]$} \\
4 & $82.5 \%$ & $\mathrm{~N} / \mathrm{A}$ & $20.63 \%$ & {$[79]$} \\
4 & $77.5 \%$ & 0.7 & $19.38 \%$ & {$[77]$} \\
4 & $68 \%$ & $\mathrm{~N} / \mathrm{A}$ & $17.00 \%$ & {$[35]$} \\
4 & $65 \%$ & $\mathrm{~N} / \mathrm{A}$ & $16.25 \%$ & {$[79]$} \\
4 & $47.27 \%$ & $\mathrm{~N} / \mathrm{A}$ & $11.82 \%$ & {$[4]$} \\
5 & $87.54 \%$ & 0.81 & $17.51 \%$ & {$[83]$} \\
6 & $79 \%$ & 0.75 & $13.17 \%$ & {$[67]$} \\
7 & $50.5 \%$ & 0.39 & $7.21 \%$ & {$[66]$} \\
9 & $41.3 \%$ & $\mathrm{~N} / \mathrm{A}$ & $4.59 \%$ & {$[76]$} \\
\hline
\end{tabular}


Table A2. List of results of reviewed studies where species classification was performed an intensity+ feature group; list sorted by species number and overall accuracy; DM-additional information for studies where trees were delineated manually.

\begin{tabular}{|c|c|c|c|c|}
\hline Number of Species & $\mathbf{O A}$ & $\kappa$ & NOCAI & Article \\
\hline 2 & $97.1 \%$ & 0.94 & $48.55 \%$ & [40] \\
\hline 2 & $97 \%$ & $\mathrm{~N} / \mathrm{A}$ & $48.50 \%$ & [113] \\
\hline 2 & $90.6 \%$ & $\mathrm{~N} / \mathrm{A}$ & $45.30 \%$ & [85] \\
\hline 2 & $90.0 \%$ & 0.80 & $45.00 \%$ & [40] \\
\hline 2 & $89 \%$ & $\mathrm{~N} / \mathrm{A}$ & $44.50 \%$ & [113] \\
\hline 2 & $86.9 \%$ & 0.74 & $43.42 \%$ & [40] \\
\hline 2 & $86 \%$ & $\mathrm{~N} / \mathrm{A}$ & $43.00 \%$ & [113] \\
\hline 2 & $83.4 \%$ & $\mathrm{~N} / \mathrm{A}$ & $41.70 \%$ & [85] \\
\hline 2 & $83 \%$ & $\mathrm{~N} / \mathrm{A}$ & $41.50 \%$ & [113] \\
\hline 2 & $78 \%$ & $\mathrm{~N} / \mathrm{A}$ & $39.00 \%$ & [113] \\
\hline 2 & $73.1 \%$ & $\mathrm{~N} / \mathrm{A}$ & $36.55 \%$ & [85] \\
\hline 3 & $92.8 \%$ & $\mathrm{~N} / \mathrm{A}$ & $30.93 \%$ & [87] \\
\hline 3 & $90.8 \%(\mathrm{DM})$ & 0.84 & $30.27 \%$ & [43] \\
\hline 3 & $89 \%$ & 0.82 & $29.67 \%$ & [60] \\
\hline 3 & $88.2 \%$ & 0.79 & $29.40 \%$ & [27] \\
\hline 3 & $88 \%$ & 0.82 & $29.33 \%$ & [62] \\
\hline 3 & $88 \%$ & 0.79 & $29.33 \%$ & [60] \\
\hline 3 & $85.42 \%$ & 0.75 & $28.47 \%$ & [34] \\
\hline 3 & $85 \%(\mathrm{DM})$ & 0.75 & $28.33 \%$ & [60] \\
\hline 3 & $85.0 \%$ & 0.72 & $28.33 \%$ & [27] \\
\hline 3 & $83 \%$ & 0.71 & $27.67 \%$ & [60] \\
\hline 3 & $82 \%(\mathrm{DM})$ & 0.71 & $27.33 \%$ & [60] \\
\hline 3 & $81.60 \%$ & 0.68 & $27.20 \%$ & [34] \\
\hline 3 & $78.1 \%$ & $\mathrm{~N} / \mathrm{A}$ & $26.03 \%$ & [100] \\
\hline 3 & $78 \%(\mathrm{DM})$ & 0.64 & $26.00 \%$ & [60] \\
\hline 3 & $78 \%$ & 0.64 & $26.00 \%$ & {$[60]$} \\
\hline 3 & $75.4 \%$ & $\mathrm{~N} / \mathrm{A}$ & $25.13 \%$ & [87] \\
\hline 3 & $74.38 \%$ & 0.56 & $24.79 \%$ & [5] \\
\hline 3 & $74 \%(\mathrm{DM})$ & 0.57 & $24.67 \%$ & [60] \\
\hline 4 & $92.5 \%$ & $\mathrm{~N} / \mathrm{A}$ & $23.13 \%$ & [79] \\
\hline 4 & $80 \%$ & $\mathrm{~N} / \mathrm{A}$ & $20.00 \%$ & [79] \\
\hline 4 & $75 \%$ & N/A & $18.75 \%$ & [35] \\
\hline 4 & $73 \%$ & $\mathrm{~N} / \mathrm{A}$ & $18.25 \%$ & [35] \\
\hline 4 & $68.0 \%$ & 0.56 & $17.60 \%$ & [80] \\
\hline 5 & $92.35 \%$ & 0.88 & $18.47 \%$ & [83] \\
\hline 5 & $69.3 \%$ & 0.58 & $13.86 \%$ & [68] \\
\hline 5 & $65.1 \%$ & 0.57 & $13.02 \%$ & [59] \\
\hline 9 & $76.5 \%$ & $\mathrm{~N} / \mathrm{A}$ & $8.50 \%$ & [76] \\
\hline 15 & $61 \%$ & 0.58 & $4.07 \%$ & [64] \\
\hline
\end{tabular}

Table A3. List of results of reviewed studies where species classification was performed with a waveform feature group; list sorted by species number and overall accuracy; DM-additional information for studies where trees were delineated manually.

\begin{tabular}{ccccc}
\hline Number of Species & OA & $\kappa$ & NOCAI & Article \\
\hline 2 & $95.7 \%$ & 0.92 & $47.85 \%$ & {$[84]$} \\
2 & $93.45 \%$ & 0.61 & $46.73 \%$ & {$[114]$} \\
2 & $93.0 \%$ & 0.72 & $46.5 \%$ & {$[37]$} \\
2 & $92.96 \%$ & 0.570 & $46.48 \%$ & {$[114]$} \\
2 & $91.7 \%$ & N/A & $45.85 \%$ & {$[36]$} \\
\hline
\end{tabular}


Table A3. Cont.

\begin{tabular}{|c|c|c|c|c|}
\hline Number of Species & OA & $\kappa$ & NOCAI & Article \\
\hline 2 & $89.76 \%$ & 0.389 & $44.88 \%$ & [114] \\
\hline 2 & $86.2 \%$ & 0.72 & $43.10 \%$ & [91] \\
\hline 2 & $85.4 \%$ & 0.71 & $42.70 \%$ & [84] \\
\hline 2 & $84.4 \%$ & 0.69 & $42.20 \%$ & [91] \\
\hline 3 & $95.1 \%$ & 0.912 & $31.70 \%$ & [99] \\
\hline 3 & $95 \%$ & 0.91 & $31.67 \%$ & [60] \\
\hline 3 & $94.8 \%$ & 0.905 & $31.60 \%$ & [99] \\
\hline 3 & $94.5 \%$ & 0.901 & $31.50 \%$ & [99] \\
\hline 3 & $92 \%$ & 0.86 & $30.67 \%$ & [60] \\
\hline 3 & $92 \%$ & 0.86 & $30.67 \%$ & [60] \\
\hline 3 & $91 \%(\mathrm{DM})$ & 0.86 & $30.33 \%$ & [60] \\
\hline 3 & $88 \%(\mathrm{DM})$ & 0.8 & $29.33 \%$ & [60] \\
\hline 3 & $88 \%$ & 0.79 & $29.33 \%$ & [60] \\
\hline 3 & 87\% (DM) & 0.79 & $29.00 \%$ & [60] \\
\hline 3 & $84 \%(\mathrm{DM})$ & 0.74 & $28.00 \%$ & [60] \\
\hline 3 & $85.0 \%$ & 0.62 & $28.33 \%$ & [94] \\
\hline 3 & $75.0 \%$ & $\mathrm{~N} / \mathrm{A}$ & $25.00 \%$ & [115] \\
\hline 3 & $73.4 \%$ & $\mathrm{~N} / \mathrm{A}$ & $24.47 \%$ & [81] \\
\hline 3 & $71.5 \%$ & $\mathrm{~N} / \mathrm{A}$ & $23.83 \%$ & [81] \\
\hline 4 & $80.4 \%$ & $\mathrm{~N} / \mathrm{A}$ & $20.10 \%$ & [36] \\
\hline 4 & $79.22 \%$ & $\mathrm{~N} / \mathrm{A}$ & $19.81 \%$ & [4] \\
\hline 4 & $75.8 \%$ & 0.68 & $18.95 \%$ & [91] \\
\hline 4 & $73.2 \%$ & 0.64 & $18.30 \%$ & [91] \\
\hline 4 & $53 \%$ & 0.44 & $13.25 \%$ & [42] \\
\hline 5 & $85.4 \%$ & 0.817 & $17.08 \%$ & [103] \\
\hline 6 & $68.6 \%$ & 0.62 & $11.43 \%$ & [91] \\
\hline 6 & $66.5 \%$ & 0.58 & $11.08 \%$ & [86] \\
\hline 6 & $66.1 \%$ & 0.59 & $11.02 \%$ & [91] \\
\hline 6 & $62.4 \%$ & 0.54 & $10.40 \%$ & [86] \\
\hline 6 & $62.0 \%$ & 0.51 & $10.33 \%$ & [86] \\
\hline 6 & $60.0 \%$ & 0.49 & $10.00 \%$ & [86] \\
\hline 6 & $59.0 \%$ & $\mathrm{~N} / \mathrm{A}$ & $9.83 \%$ & [36] \\
\hline 6 & $58.2 \%$ & 0.47 & $9.70 \%$ & [86] \\
\hline 6 & $57.1 \%$ & 0.46 & $9.52 \%$ & [86] \\
\hline
\end{tabular}

Table A4. List of studies with overall accuracy greater than the median overall accuracy of all studies for each number of species with information about the quartiles; QM-U—the range from the median to upper quartile, QU-UW- the range from the upper quartile to the upper whisker; list sorted by species number and OA.

\begin{tabular}{cccccc}
\hline Number of Species & Quartile & Feature Group & OA & $\kappa$ & Article \\
\hline 2 & QU-UW & intensity+ & $97.1 \%$ & 0.94 & {$[40]$} \\
2 & QU-UW & intensity+ & $97 \%$ & N/A & {$[113]$} \\
2 & QU-UW & waveform & $95.7 \%$ & 0.92 & {$[84]$} \\
2 & QU-UW & geometry & $95.0 \%$ & N/A & {$[75]$} \\
2 & QU-UW & waveform & $93.45 \%$ & 0.61 & {$[114]$} \\
2 & QU-UW & waveform & $93.0 \%$ & 0.72 & {$[37]$} \\
2 & QM-U & waveform & $92.96 \%$ & 0.570 & {$[114]$} \\
2 & QM-U & waveform & $91.7 \%$ & N/A & {$[36]$} \\
2 & QM-U & intensity+ & $90.6 \%$ & N/A & {$[85]$} \\
2 & QM-U & intensity+ & $90.0 \%$ & 0.80 & {$[40]$} \\
2 & QM-U & waveform & $89.76 \%$ & 0.389 & {$[114]$} \\
\hline
\end{tabular}


Table A4. Cont.

\begin{tabular}{|c|c|c|c|c|c|}
\hline Number of Species & Quartile & Feature Group & OA & $\kappa$ & Article \\
\hline 3 & QU-UW & waveform & $95.1 \%$ & 0.912 & [99] \\
\hline 3 & QU-UW & waveform & $95 \%$ & 0.91 & [60] \\
\hline 3 & QU-UW & waveform & $94.8 \%$ & 0.905 & [99] \\
\hline 3 & QU-UW & waveform & $94.5 \%$ & 0.901 & [99] \\
\hline 3 & QU-UW & intensity+ & $92.8 \%$ & $\mathrm{~N} / \mathrm{A}$ & [87] \\
\hline 3 & QU-UW & waveform & $92 \%$ & 0.86 & [60] \\
\hline 3 & QU-UW & waveform & $92 \%$ & 0.86 & [60] \\
\hline 3 & QU-UW & waveform & $91 \%$ & 0.86 & [60] \\
\hline 3 & QU-UW & intensity+ & $90.8 \%$ & 0.84 & [43] \\
\hline 3 & QU-UW & intensity+ & $89 \%$ & 0.82 & {$[60]$} \\
\hline 3 & QM-U & geometry & $88.6 \%$ & $\mathrm{~N} / \mathrm{A}$ & [87] \\
\hline 3 & QM-U & intensity+ & $88.2 \%$ & 0.79 & [27] \\
\hline 3 & QM-U & intensity+ & $88 \%$ & 0.82 & [62] \\
\hline 3 & QM-U & waveform & $88 \%$ & 0.8 & [60] \\
\hline 3 & QM-U & intensity+ & $88 \%$ & 0.79 & {$[60]$} \\
\hline 3 & QM-U & waveform & $88 \%$ & 0.79 & [60] \\
\hline 3 & QM-U & waveform & $87 \%$ & 0.79 & [60] \\
\hline 3 & QM-U & geometry & $86.3 \%$ & 0.759 & [63] \\
\hline 3 & QM-U & intensity+ & $85.42 \%$ & 0.75 & [34] \\
\hline 3 & QM-U & geometry & $85.4 \%$ & 0.739 & [63] \\
\hline 4 & QU-UW & geometry & $93.7 \%$ & $\mathrm{~N} / \mathrm{A}$ & [78] \\
\hline 4 & QU-UW & intensity+ & $92.5 \%$ & $\mathrm{~N} / \mathrm{A}$ & [79] \\
\hline 4 & QU-UW & geometry & $89.7 \%$ & 0.86 & [66] \\
\hline 4 & QU-UW & geometry & $85 \%$ & $\mathrm{~N} / \mathrm{A}$ & [79] \\
\hline 4 & QU-UW & geometry & $82.5 \%$ & $\mathrm{~N} / \mathrm{A}$ & [79] \\
\hline 4 & QM-U & waveform & $80.4 \%$ & $\mathrm{~N} / \mathrm{A}$ & [36] \\
\hline 4 & QM-U & intensity+ & $80 \%$ & $\mathrm{~N} / \mathrm{A}$ & [79] \\
\hline 4 & QM-U & waveform & $79.22 \%$ & $\mathrm{~N} / \mathrm{A}$ & {$[4]$} \\
\hline 4 & $\widehat{\mathrm{QM}}-\mathrm{U}$ & geometry & $77.5 \%$ & 0.7 & {$[77]$} \\
\hline 6 & QU-UW & geometry & $79 \%$ & 0.75 & [67] \\
\hline 6 & QU-UW & waveform & $68.6 \%$ & 0.62 & [91] \\
\hline 6 & Q̄U-UW & waveform & $66.5 \%$ & 0.58 & [86] \\
\hline 6 & QM-U & waveform & $66.1 \%$ & 0.59 & [91] \\
\hline 6 & QM-U & waveform & $62.4 \%$ & 0.54 & [86] \\
\hline
\end{tabular}

\section{References}

1. White, J.C.; Coops, N.C.; Wulder, M.A.; Vastaranta, M.; Hilker, T.; Tompalski, P. Remote sensing technologies for enhancing forest inventories: A review. Can. J. Remote Sens. 2016, 42, 619-641. [CrossRef]

2. Kangas, A.; Maltamo, M. Forest Inventory: Methodology and Applications; Springer Science \& Business Media: Dordrecht, The Netherlands, 2006; Volume 10. [CrossRef]

3. Dalponte, M.; Bruzzone, L.; Gianelle, D. Tree species classification in the Southern Alps based on the fusion of very high geometrical resolution multispectral/hyperspectral images and LiDAR data. Remote Sens. Environ. 2012, 123, 258-270. [CrossRef]

4. Heinzel, J.; Koch, B. Investigating multiple data sources for tree species classification in temperate forest and use for single tree delineation. Int. J. Appl. Earth Obs. Geoinf. 2012, 18, 101-110. [CrossRef]

5. Ørka, H.; Dalponte, M.; Gobakken, T.; Næsset, E.; Ene, L. Characterizing forest species composition using multiple remote sensing data sources and inventory approaches. Scand. J. For. Res. 2013, 28. [CrossRef]

6. Peterson, D.L.; Aber, J.D.; Matson, P.A.; Card, D.H.; Swanberg, N.; Wessman, C.; Spanner, M. Remote sensing of forest canopy and leaf biochemical contents. Remote Sens. Environ. 1988, 24, 85-108. [CrossRef]

7. Baret, F.; Vanderbilt, V.C.; Steven, M.D.; Jacquemoud, S. Use of spectral analogy to evaluate canopy reflectance sensitivity to leaf optical properties, Remote Sens. Environ. 1994, 48, 253-260. [CrossRef]

8. Asner, G.P.; Martin, R.E. Airborne spectranomics: Mapping canopy chemical and taxonomic diversity in tropical forests. Front. Ecol. Environ. 2009, 7, 269-276. [CrossRef] 
9. Schimel, D.S.; Asner, G.P.; Moorcroft, P. Observing changing ecological diversity in the Anthropocene. Front. Ecol. Environ. 2013, 11, 129-137. [CrossRef]

10. Baldeck, C.A.; Asner, G.P.; Martin, R.E.; Anderson, C.B.; Knapp, D.E.; Kellner, J.R.; Wright, S.J. Operational tree species mapping in a diverse tropical forest with airborne imaging spectroscopy. PLoS ONE 2015, 10, e0118403. [CrossRef]

11. Brosofske, K.D.; Froese, R.E.; Falkowski, M.J.; Banskota, A. A review of methods for mapping and prediction of inventory attributes for operational forest management. For. Sci. 2014, 60, 733-756. [CrossRef]

12. Maltamo, M.; Næsset, E.; Vauhkonen, J. Forestry applications of airborne laser scanning. Concepts Case Stud. Manag. Ecosys 2014, 27, 460. [CrossRef]

13. Kelly, M.; Di Tommaso, S. Mapping forests with Lidar provides flexible, accurate data with many uses. Calif. Agric. 2015, 69, 14-20. [CrossRef]

14. Krzystek, P.; Serebryanyk, A.; Schnörr, C.; Červenka, J.; Heurich, M. Large-Scale Mapping of Tree Species and Dead Trees in Šmava National Park and Bavarian Forest National Park Using Lidar and Multispectral Imagery. Remote Sens. 2020, $12,661$. [CrossRef]

15. Bachman, C.G. Laser Radar Systems and Techniques; Artech House: Dedham, MA, USA, 1979.

16. Wehr, A.; Lohr, U. Airborne laser scanning-An introduction and overview. ISPRS J. Photogramm. Remote Sens. 1999, 54, 68-82. [CrossRef]

17. Pritchard, D.; Sperner, J.; Hoepner, S.; Tenschert, R. Terrestrial laser scanning for heritage conservation: The Cologne Cathedral documentation project. ISPRS Ann. Photogramm. Remote Sens. Spat. Inf. Sci. 2017, 4. [CrossRef]

18. Pérez-Álvarez, R.; de Luis, J.; Pereda-García, R.; Fernández-Maroto, G.; Malagón-Picón, B. 3D Documentation with TLS of Caliphal Gate (Ceuta, Spain). Appl. Sci. 2020, 10, 5377. [CrossRef]

19. $\mathrm{Pu}, \mathrm{S}$. Generating building outlines from terrestrial laser scanning. ISPRSO8 B 2008, 5, 451-455.

20. Nowak, R.; Orłowicz, R.; Rutkowski, R. Use of TLS (LiDAR) for building diagnostics with the example of a historic building in Karlino. Buildings 2020, 10, 24. [CrossRef]

21. Suchocki, C.; Damięcka-Suchocka, M.; Katzer, J.; Janicka, J.; Rapinski, J.; Stałowska, P. Remote Detection of Moisture and Bio-Deterioration of Building Walls by Time-of-Flight and Phase-Shift Terrestrial Laser Scanners. Remote Sens. 2020, 12, 1708. [CrossRef]

22. Guan, H.; Li, J.; Cao, S.; Yu, Y. Use of mobile LiDAR in road information inventory: A review. Int. J. Image Data Fusion 2016, 7, 219-242. [CrossRef]

23. Truong-Hong, L.; Laefer, D.F. Documentation of bridges by terrestrial laser scanner. In Proceedings of the IABSE Geneva Conference 2015, Geneva, Switzerland, 23-25 September 2015. [CrossRef]

24. Artese, S.; Zinno, R. TLS for Dynamic Measurement of the Elastic Line of Bridges. Appl. Sci. 2020, 10, 1182. [CrossRef]

25. Hyyppä, J.; Yu, X.; Hyyppä, H.; Vastaranta, M.; Holopainen, M.; Kukko, A.; Kaartinen, H.; Jaakkola, A.; Vaaja, M.; Koskinen, J.; et al. Advances in forest inventory using airborne laser scanning. Remote Sens. 2012, 4, 1190-1207. [CrossRef]

26. Latifi, H.; Fassnacht, F.E.; Müller, J.; Tharani, A.; Dech, S.; Heurich, M. Forest inventories by LiDAR data: A comparison of single tree segmentation and metric-based methods for inventories of a heterogeneous temperate forest. Int. J. Appl. Earth Obs. Geoinf. 2015, 42, 162-174. [CrossRef]

27. Kukkonen, M.; Maltamo, M.; Korhonen, L.; Packalen, P. Multispectral airborne LiDAR data in the prediction of boreal tree species composition. IEEE Trans. Geosci. Remote Sens. 2019, 57, 3462-3471. [CrossRef]

28. Prieto, I.; Izkara, J.L.; Usobiaga, E. The application of lidar data for the solar potential analysis based on urban 3D model. Remote Sens. 2019, 11, 2348. [CrossRef]

29. Wang, X.; Chan, T.O.; Liu, K.; Pan, J.; Luo, M.; Li, W.; Wei, C. A robust segmentation framework for closely packed buildings from airborne LiDAR point clouds. Int. J. Remote Sens. 2020, 41, 5147-5165. [CrossRef]

30. Heritage, G.; Large, A. Laser Scanning for the Environmental Sciences; John Wiley \& Sons: Hoboken, NJ, USA, 2009. [CrossRef]

31. Pyysalo, U.; Hyyppa, H. Reconstructing tree crowns from laser scanner data for feature extraction. Int. Arch. Photogramm. Remote Sens. Spat. Inf. Sci. 2002, 34, 218-221.

32. Solberg, S.; Naesset, E.; Bollandsas, O.M. Single tree segmentation using airborne laser scanner data in a structurally heterogeneous spruce forest. Photogramm. Eng. Remote Sens. 2006, 72, 1369-1378. [CrossRef]

33. Chamberlain, C.P.; Meador, A.J.S.; Thode, A.E. Airborne lidar provides reliable estimates of canopy base height and canopy bulk density in southwestern ponderosa pine forests. For. Ecol. Manag. 2020, 481, 118695. [CrossRef]

34. Yu, X.; Hyyppä, J.; Litkey, P.; Kaartinen, H.; Vastaranta, M.; Holopainen, M. Single-sensor solution to tree species classification using multispectral airborne laser scanning, Remote Sens. 2017, 9, 108. [CrossRef]

35. Krüger geb. Amiri, N.; Heurich, M.; Krzystek, P.; Skidmore, A. Feature Relevance Assessment of Multispectral Airborne LiDAR Data for Tree Species Classification. ISPRS Int. Arch. Photogramm. Remote Sens. Spat. Inf. Sci. 2018, XLII-3, 31-34. [CrossRef]

36. Heinzel, J.; Koch, B. Exploring full-waveform LiDAR parameters for tree species classification. Int. J. Appl. Earth Obs. Geoinf. 2011, 13, 152-160. [CrossRef]

37. Yao, W.; Krzystek, P.; Heurich, M. Tree species classification and estimation of stem volume and DBH based on single tree extraction by exploiting airborne full-waveform LiDAR data. Remote Sens. Environ. 2012, 123, 368-380. [CrossRef]

38. Naesset, E. Estimating timber volume of forest stands using airborne laser scanner data. Remote Sens. Environ. 1997, 61, 246-253. [CrossRef] 
39. Hyyppa, J.; Kelle, O.; Lehikoinen, M.; Inkinen, M. A segmentation-based method to retrieve stem volume estimates from 3-D tree height models produced by laser scanners. IEEE Trans. Geosci. Remote Sens. 2001, 39, 969-975. [CrossRef]

40. Ørka, H.O.; Næsset, E.; Bollandsås, O.M. Effects of different sensors and leaf-on and leaf-off canopy conditions on echo distributions and individual tree properties derived from airborne laser scanning. Remote Sens. Environ. 2010, 114, 1445-1461. [CrossRef]

41. Bont, L.; Hill, A.; Waser, L.; Bürgi, A.; Ginzler, C.; Blattert, C. Airborne-laser-scanning-derived auxiliary information discriminating between broadleaf and conifer trees improves the accuracy of models for predicting timber volume in mixed and heterogeneously structured forests. For. Ecol. Manag. 2020, 459, 117856. [CrossRef]

42. Sarrazin, D.; van Aardt, J.; Asner, G.; Mcglinchy, J.; Messinger, D.; Wu, J. Fusing small-footprint waveform LiDAR and hyperspectral data for canopy-level species classification and herbaceous biomass modeling in savanna ecosystems. Can. J. Remote Sens. 2011, 37, 653-665. [CrossRef]

43. Korpela, I.; Ørka, H.; Maltamo, M.; Tokola, T.; Hyyppä, J.; Tokola, M.; Maltamo, T. Tree Species Classification Using Airborne LiDAR -Effects of Stand and Tree Parameters, Downsizing of Training Set, Intensity Normalization, and Sensor Type. Silva Fenn. 2010, 44. [CrossRef]

44. Culvenor, D. A Spatial Clustering Approach to Automated Tree Crown Delineation; Pacific Forestry Centre: Victoria, BC, Canada, 1998; pp. 67-88.

45. Voss, M.; Sugumaran, R. Seasonal effect on tree species classification in an urban environment using hyperspectral data, LiDAR, and an object-oriented approach. Sensors 2008, 8, 3020-3036. [CrossRef]

46. Reitberger, J.; Schnörr, C.; Krzystek, P.; Stilla, U. 3D segmentation of single trees exploiting full waveform LIDAR data. ISPRS J. Photogramm. Remote Sens. 2009, 64, 561-574. [CrossRef]

47. Yu, X.; Hyyppä, J.; Holopainen, M.; Vastaranta, M. Comparison of Area-Based and Individual Tree-Based Methods for Predicting Plot-Level Forest Attributes. Remote Sens. 2010, 2. [CrossRef]

48. Yao, W. A Sensitivity Analysis for a Novel Individual Tree Segmentation Algorithm Using 3D Lidar Point Cloud Data; Silvilaser: Vancouver, BC, Canada. 2012.

49. Eysn, L.; Hollaus, M.; Lindberg, E.; Berger, F.; Monnet, J.M.; Dalponte, M.; Kobal, M.; Pellegrini, M.; Lingua, E.; Mongus, D.; Pfeifer, N. A Benchmark of Lidar-Based Single Tree Detection Methods Using Heterogeneous Forest Data from the Alpine Space. Forests 2015, 6, 1721-1747. [CrossRef]

50. Smith, S.; Holland, D.; Longley, P. The importance of understanding error in lidar digital elevation models. Int. Arch. Photogramm. Remote Sens. Spat. Inf. Sci. 2004, 35, 996-1001.

51. Tiede, D.; Hochleitner, G.; Blaschke, T. A full GIS-based workflow for tree identification and tree crown delineation using laser scanning. ISPRS Workshop CMRT 2005, 5, 2005.

52. Zhao, K.; Popescu, S. Hierarchical watershed segmentation of canopy height model for multi-scale forest inventory. Proc. ISPRS Work. Group 2007, 442, 436.

53. Zhong, L.; Cheng, L.; Xu, H.; Wu, Y.; Chen, Y.; Li, M. Segmentation of Individual Trees From TLS and MLS Data. IEEE J. Sel. Top. Appl. Earth Obs. Remote Sens. 2016, 1-14. [CrossRef]

54. Xu, S.; Ye, N.; Xu, S.; Zhu, F. A supervoxel approach to the segmentation of individual trees from LiDAR point clouds. Remote Sens. Lett. 2018, 9, 515-523. [CrossRef]

55. Xu, Y.; Sun, Z.; Hoegner, L.; Stilla, U.; Yao, W. Instance Segmentation of Trees in Urban Areas from MLS Point Clouds Using Supervoxel Contexts and Graph-Based Optimization. In Proceedings of the 10th IAPR Workshop on Pattern Recognition in Remote Sensing (PRRS), Beijing, China, 19-20 August 2018; pp. 1-5. [CrossRef]

56. Anandakumar, R.; Nidamanuri, R.; Krishnan, R. Assessment of various parameters on 3D semantic object-based point cloud labelling on urban LiDAR dataset. Geocarto Int. 2018, 34, 1-29. [CrossRef]

57. Anandakumar, R.; Nidamanuri, R.; Krishnan, R. Individual tree detection from airborne laser scanning data based on supervoxels and local convexity. Remote Sens. Appl. Soc. Environ. 2019, 15, 100242. [CrossRef]

58. Ørka, H.; Næsset, E.; Bollandsås, O. Classifying species of individual trees by intensity and structure features derived from airborne laser scanner data. Remote Sens. Environ. 2009, 113, 1163-1174. [CrossRef]

59. Shi, Y.; Skidmore, A.; Holzwarth, S.; Heiden, U.; Pinnel, N.; Zhu, X.; Heurich, M. Tree species classification using plant functional traits from LiDAR and hyperspectral data. Int. J. Appl. Earth Obs. Geoinf. 2018, 73. [CrossRef]

60. Hovi, A.; Korhonen, L.; Vauhkonen, J.; Korpela, I. LiDAR waveform features for tree species classification and their sensitivity to tree- and acquisition related parameters. Remote Sens. Environ. 2016, 173, 224-237. [CrossRef]

61. Ba, A.; Laslier, M.; Dufour, S.; Hubert-Moy, L. Riparian Trees Genera Identification Based on Leaf-on/Leaf-off Airborne Laser Acanner Data and Machine Learning Classifiers in Northern France. Int. J. Remote Sens. 2019. [CrossRef]

62. Holmgren, J.; Persson, A.; Söderman, U. Species identification of individual trees by combining high resolution LiDAR data with multi-spectral images. Int. J. Remote Sens. Int. Remote Sens. 2008, 29, 1537-1552. [CrossRef]

63. Dalponte, M.; Ørka, H.; Ene, L.; Gobakken, T.; Næsset, E. Tree crown delineation and tree species classification in boreal forests using hyperspectral and ALS data. Remote Sens. Environ. 2014, 140, 306-317. [CrossRef]

64. Liu, L.; Coops, N.; Aven, N.; Pang, Y. Mapping urban tree species using integrated airborne hyperspectral and LiDAR remote sensing data. Remote Sens. Environ. 2017, 200, 170-182. [CrossRef] 
65. Liao, W.; Van Coillie, F.; Gao, L.; Li, L.; Chanussot, J. Deep Learning for Fusion of APEX Hyperspectral and Full-waveform LiDAR Remote Sensing Data for Tree Species Mapping. IEEE Access 2018, 6, 68716-68729. [CrossRef]

66. Yang, G.; Zhao, Y.; Li, B.; Ma, Y.; Li, R.; Jing, J.; Dian, Y. Tree Species Classification by Employing Multiple Features Acquired from Integrated Sensors. J. Sens. 2019, 2019, 1-12. [CrossRef]

67. Li, Q.; Wong, F.; Fung, T. Classification of Mangrove Species Using Combined WordView-3 and LiDAR Data in Mai Po Nature Reserve, Hong Kong. Remote Sens. 2019, 11, 2114. [CrossRef]

68. Shi, Y.; Skidmore, A.; Heurich, M. Improving LiDAR-based tree species mapping in Central European mixed forests using multi-temporal digital aerial colour-infrared photographs. Int. J. Appl. Earth Obs. Geoinf. 2019, 84. [CrossRef]

69. Cohen, J. A Coefficient of Agreement for Nominal Scales. Psychol. Bull. 1960, 20, 37. [CrossRef]

70. Landis, J.; Koch, G. The Measurement of Observer Agreement For Categorical Data. Biometrics 1977, 33, 159-174. [CrossRef] [PubMed]

71. Wang, K.; Liu, X. A Review: Individual Tree Species Classification Using Integrated Airborne LiDAR and Optical Imagery with a Focus on the Urban Environment. Forests 2018, 10, 1. [CrossRef]

72. Zhang, C.; Qiu, F. Mapping individual tree species in an urban forest using airborne lidar data and hyperspectral imagery. Photogramm. Eng. Remote Sens. 2012, 78, 1079-1087. [CrossRef]

73. Koenig, K.; Höfle, B. Full-Waveform Airborne Laser Scanning in Vegetation Studies-A Review of Point Cloud and Waveform Features for Tree Species Classification. Forests 2016, 7, 198. [CrossRef]

74. Ørka, H.; Næsset, E.; Bollandsås, O. Utilizing Airborne Laser Intensity for Tree Species Classification. Int. Arch. Photogramm. Remote Sens. Spat. Inf. Sci. 2012, 36, 300-304.

75. Holmgren, J.; Persson, A. Identifying species of individual trees using airborne laser scanner. Remote Sens. Environ. 2004, 90, 415-423. [CrossRef]

76. Axelsson, A.; Lindberg, E.; Olsson, H. Exploring Multispectral ALS Data for Tree Species Classification. Remote Sens. 2018, 10, 183. [CrossRef]

77. Li, J.; Hu, B.; Noland, T. Classification of tree species based on structural features derived from high density LiDAR data. Agric. For. Meteorol. 2013, 171-172, 104-114. [CrossRef]

78. Harikumar, A.; Bovolo, F.; Bruzzone, L. An Internal Crown Geometric Model for Conifer Species Classification With High-Density LiDAR Data. IEEE Trans. Geosci. Remote Sens. 2017, 55, 2924-2940. [CrossRef]

79. Lin, Y.; Hyyppä, J. A comprehensive but efficient framework of proposing and validating feature parameters from airborne LiDAR data for tree species classification. Int. J. Appl. Earth Obs. Geoinf. 2016, 46, 45-55. [CrossRef]

80. Suratno, A.; Seielstad, C.; Queen, L. Tree species identification in mixed coniferous forest using airborne laser scanning. ISPRS J. Photogramm. Remote Sens. ISPRS Photogramm. 2009, 64, 683-693. [CrossRef]

81. Yu, X.; Litkey, P.; Hyyppä, J.; Holopainen, M.; Vastaranta, M. Assessment of Low Density Full-Waveform Airborne Laser Scanning for Individual Tree Detection and Tree Species Classification. Forests 2014, 5, 1011-1031. [CrossRef]

82. Höfle, B.; Hollaus, M.; Hagenauer, J. Urban vegetation detection using radiometrically calibrated small-footprint full-waveform airborne LiDAR data. ISPRS J. Photogramm. Remote Sens. 2012, 67, 134-147. [CrossRef]

83. You, H.; Lei, P.; Li, M.; Ruan, F. Forest Species Classification Based on Three-dimensional Coordinate and Intensity Information of Airborne LiDAR Data with Random Forest Method. ISPRS Int. Arch. Photogramm. Remote Sens. Spat. Inf. Sci. 2020, XLII-3/W10, 117123. [CrossRef]

84. Reitberger, J.; Krzystek, P.; Stilla, U. Analysis of full waveform LIDAR data for the classification of deciduous and coniferous trees. Int. J. Remote Sens. 2008, 29, 1407-1431. [CrossRef]

85. Kim, S.; Mcgaughey, R.; Andersen, H.E.; Schreuder, G. Tree species differentiation using intensity data derived from leaf-on and leaf-off airborne laser scanner data. Remote Sens. Environ. 2009, 113, 1575-1586. [CrossRef]

86. Shi, Y.; Skidmore, A.; Heurich, M. Important LiDAR metrics for discriminating forest tree species in Central Europe. ISPRS J. Photogramm. Remote Sens. 2018, 137, 163-174. [CrossRef]

87. Zhang, Z.; Liu, X. Support vector machines for tree species identification using LiDAR-derived structure and intensity variables. Geocarto Int. 2012, 28, 1-15. [CrossRef]

88. Budei, B.; St-Onge, B.; Hopkinson, C.; Audet, F.A. Identifying the genus or species of individual trees using a three-wavelength airborne lidar system. Remote Sens. Environ. 2017, 204. [CrossRef]

89. Pirotti, F. Analysis of full-waveform LiDAR data for forestry applications: A review of investigations and methods. Iforest Biogeosci. For. 2011, 100-106. [CrossRef]

90. Wagner, W.; Ullrich, A.; Ducic, V.; Melzer, T.; Studnicka, N. Gaussian decomposition and calibration of a novel small-footprint full-waveform digitising airborne laser scanner. ISPRS J. Photogramm. Remote Sens. 2006, 60, 100-112. [CrossRef]

91. Cao, L.; Coops, N.; Innes, J.; Dai, J.; Ruan, H.; She, G. Tree species classification in subtropical forests using small-footprint full-waveform LiDAR data. Int. J. Appl. Earth Obs. Geoinf. 2016, 49, 39-51. [CrossRef]

92. Drake, J.B.; Dubayah, R.O.; Clark, D.B.; Knox, R.G.; Blair, J.; Hofton, M.A.; Chazdon, R.L.; Weishampel, J.F.; Prince, S. Estimation of tropical forest structural characteristics using large-footprint LiDAR. Remote Sens. Environ. 2002, 79, 305-319. [CrossRef]

93. Duong, V. Processing and Application of ICESat Large Footprint Full Waveform Laser Range Data. Ph.D. Thesis, Delft University of Technology, Delft, The Netherlands, 2010. 
94. Hollaus, M.; Mücke, W.; Höfle, B.; Dorigo, W.; Pfeifer, N.; Wagner, W.; Bauerhansl, C.; Regner, B. Tree species classification based on full-waveform airborne laser scanning data. SilviLaser 2009, 54, 14-16.

95. Zhou, T.; Popescu, S.; Lawing, A.M.; Eriksson, M.; Strimbu, B.; Burkner, P. Bayesian and Classical Machine Learning Methods: A Comparison for Tree Species Classification with LiDAR Waveform Signatures. Remote Sens. 2018, 10, 39. [CrossRef]

96. Brandtberg, T.; Warner, T.; Landenberger, R.; Mcgraw, J. Detection and analysis of individual leaf-off tree crowns in small footprint, high sampling density lidar data from the eastern deciduous forest in North America. Remote Sens. Environ. 2003, 85, 290-303. [CrossRef]

97. Wasser, L.; Day, R.; Chasmer, L.; Taylor, A. Influence of Vegetation Structure on Lidar-derived Canopy Height and Fractional Cover in Forested Riparian Buffers During Leaf-Off and Leaf-On Conditions. PLoS ONE 2013, 8, e54776. [CrossRef]

98. Sumnall, M.; Hill, R.; Hinsley, S. Comparison of small-footprint discrete return and full waveform airborne lidar data for estimating multiple forest variables. Remote Sens. Environ. 2015, 173. [CrossRef]

99. Blomley, R.; Hovi, A.; Weinmann, M.; Hinz, S.; Korpela, I.; Jutzi, B. Tree species classification using within crown localization of waveform LiDAR attributes. ISPRS J. Photogramm. Remote Sens. 2017, 133, 142-156. [CrossRef]

100. Vauhkonen, J.; Korpela, I.; Maltamo, M.; Tokola, T. Imputation of single-tree attributes using airborne laser scanning-based height, intensity, and alpha shape metrics. Remote Sens. Environ. 2010, 114, 1263-1276. [CrossRef]

101. Ballanti, L.; Blesius, L.; Hines, E.; Kruse, B. Tree Species Classification Using Hyperspectral Imagery: A Comparison of Two Classifiers. Remote Sens. 2016, 8, 445. [CrossRef]

102. Jones, T.; Coops, N.; Sharma, T. Assessing the utility of airborne hyperspectral and LiDAR data for species distribution mapping in the coastal Pacific Northwest, Canada. Remote Sens. Environ. 2010, 114, 2841-2852. [CrossRef]

103. Vaughn, N.; Moskal, L.; Turnblom, E. Tree Species Detection Accuracies Using Discrete Point Lidar and Airborne Waveform Lidar. Remote Sens. 2012, 4, 377-403. [CrossRef]

104. Nguyen, H.; Demir, B.; Dalponte, M. Weighted Support Vector Machines for Tree Species Classification Using Lidar Data. In Proceedings of the IGARSS 2019-2019 IEEE International Geoscience and Remote Sensing Symposium, Yokohama, Japan, 28 July-2 August 2019; pp. 6740-6743. [CrossRef]

105. Breiman, L. Random Forests. Mach. Learn. Vol. 2001, 45, 5-32. [CrossRef]

106. Cortes, C.; Vapnik, V. Support-vector networks. Chem. Biol. Drug Des. 2009, 297, 273-297. [CrossRef]

107. Fassnacht, F.; Latifi, H.; Stereńczak, K.; Modzelewska, A.; Lefsky, M.; Waser, L.; Straub, C.; Ghosh, A. Review of studies on tree species classification from remotely sensed data. Remote Sens. Environ. 2016, 186, 64-87. [CrossRef]

108. Polewski, P.P. Reconstruction of Standing and Fallen Single Dead Trees in Forested Areas from LiDAR Data and Aerial Imagery. Ph.D. Thesis, Technische Universität München, München, Germany, 2017.

109. Polewski, P.; Yao, W.; Heurich, M.; Krzystek, P.; Stilla, U. Free Shape Context descriptors optimized with genetic algorithm for the detection of dead tree trunks in ALS point clouds. ISPRS Geospat. Week 2015, W5, 41-48. [CrossRef]

110. Jayathunga, S.; Owari, T.; Tsuyuki, S. Analysis of forest structural complexity using airborne LiDAR data and aerial photography in a mixed conifer-broadleaf forest in northern Japan. J. For. Res. 2018, 29, 479-493. [CrossRef]

111. Latifi, H.; Heurich, M.; Hartig, F.; Müller, J.; Krzystek, P.; Jehl, H.; Dech, S. Estimating over-and understorey canopy density of temperate mixed stands by airborne LiDAR data. For. Int. J. For. Res. 2016, 89, 69-81. [CrossRef]

112. Zielewska-Büttner, K.; Heurich, M.; Müller, J.; Braunisch, V. Remotely sensed single tree data enable the determination of habitat thresholds for the three-toed woodpecker (Picoides tridactylus). Remote Sens. 2018, 10, 1972. [CrossRef]

113. Vauhkonen, J.; Hakala, T.; Suomalainen, J.; Kaasalainen, S.; Nevalainen, O.; Vastaranta, M.; Holopainen, M.; Hyyppä, J. Classification of Spruce and Pine Trees Using Active Hyperspectral LiDAR. IEEE Geosci. Remote Sens. Lett. 2013, 10, $1138-1141$. [CrossRef]

114. Bruggisser, M.; Roncat, A.; Schaepman, M.; Morsdorf, F. Retrieval of higher order statistical moments from full-waveform LiDAR data for tree species classification. Remote Sens. Environ. 2017, 196, 28-41. [CrossRef]

115. Vaughn, N.; Moskal, L.; Turnblom, E. Fourier transformation of waveform Lidar for species recognition. Remote Sens. Lett. 2011, 2,347-356. [CrossRef] 